\title{
The Lipid Activation Mechanism of a Transmembrane Potassium Channel
}

Collin G. Borcik ${ }^{\dagger}$, Derek B. Versteeg ${ }^{\dagger}$, Reza Amani ${ }^{\dagger}$, Maryam Yekefallah, Nazmul H. Khan, and Benjamin J. Wylie*.

Department of Chemistry and Biochemistry, Texas Tech University, Lubbock, TX 79409 


\section{Supporting Text:}

To fully understand the time dependent evolution of ${ }^{1} \mathrm{H}-{ }^{1} \mathrm{H}$ spin diffusion, we found a single $\mathrm{R}_{1}$ value was insufficient to describe the relaxation rate associated with the buildup of protein polarization from water as a function of ${ }^{1} \mathrm{H}-{ }^{-1} \mathrm{H}$ spin diffusion times. ${ }^{1} \mathrm{H}-{ }^{-1} \mathrm{H}$ cross relaxational rates were investigated by Najbauer et al. who proposed a cross relaxation model that fits these ${ }^{1} \mathrm{H}_{\text {water }}{ }^{-1} \mathrm{H}_{\text {protein }}$ spin diffusion buildup curves to high precision assuming fast spinning and extensive deuteration attenuate intra-protein spin diffusion. Additionally, the different rates of polarization buildup and relaxation between the SM and the TQ spectra suggest physiologically relevant interpretation of dynamic relaxation. The ${ }^{1} \mathrm{H}-{ }^{13} \mathrm{C}$ HETCOR experiment shows the SM lipid resonances are completely filtered out through the implementation of the $T_{2}$ filter, but the $\mathrm{TQ}$ lipid ${ }^{1} \mathrm{H}$ resonances do correlate to $\mathrm{NA}-{ }^{13} \mathrm{C}$-lipid signals without the appearance of any discernable protein peaks (Figure S1). We are confident that there is no magnetization that comes to KirBac1.1 via lipid ${ }^{1} \mathrm{Hs}$ as there are no resonances that correspond to lipid associated transmembrane residues in the $\mathrm{T}_{2}$ filtered ${ }^{13} \mathrm{C}-{ }^{13} \mathrm{C} 2 \mathrm{D}$. Therefore, we can assert that all polarization is transferring from the water species, and that intra-protein polarization transfer does severely impact data analysis in the regime of moderate spinning and fully protonated proteins. Our interpretation follows below.

REDOR simulations: For all the simulation, three carbon atoms and a phosphorus atom were considered. Dipolar couplings were calculated to represent the distance between atoms. All simulation were run considering a $600 \mathrm{MHz}$ field strength, and $25 \mathrm{kHz}$ spinning rate. For each simulation, 18 gamma angles were considered. Rep320 crystal file was used and each simulation used 1024 points.

\begin{tabular}{|l|l|}
\hline Distance & Dipole coupling \\
\hline $8.0 \AA$ between ${ }^{31} \mathrm{P}-13 \mathrm{C}$ & $23.90 \mathrm{~Hz}$ \\
\hline $7.4 \AA$ between ${ }^{31} \mathrm{P}-{ }^{13} \mathrm{C}$ & $30.20 \mathrm{~Hz}$ \\
\hline $7.3 \AA$ between ${ }^{31} \mathrm{P}-{ }^{13} \mathrm{C}$ & $31.46 \mathrm{~Hz}$ \\
\hline $6.5 \AA$ between ${ }^{31} \mathrm{P}-{ }^{13} \mathrm{C}$ & $44.57 \mathrm{~Hz}$ \\
\hline $6.3 \AA$ between ${ }^{31} \mathrm{P}-{ }^{13} \mathrm{C}$ & $48.95 \mathrm{~Hz}$ \\
\hline $5.0 \AA$ between ${ }^{31} \mathrm{P}-13 \mathrm{C}$ & $97.92 \mathrm{~Hz}$ \\
\hline $4.9 \AA$ between ${ }^{31} \mathrm{P}-{ }^{13} \mathrm{C}$ & $104.00 \mathrm{~Hz}$ \\
\hline $4.6 \AA$ between ${ }^{31} \mathrm{P}-{ }^{13} \mathrm{C}$ & $125.75 \mathrm{~Hz}$ \\
\hline
\end{tabular}


Supporting Information:

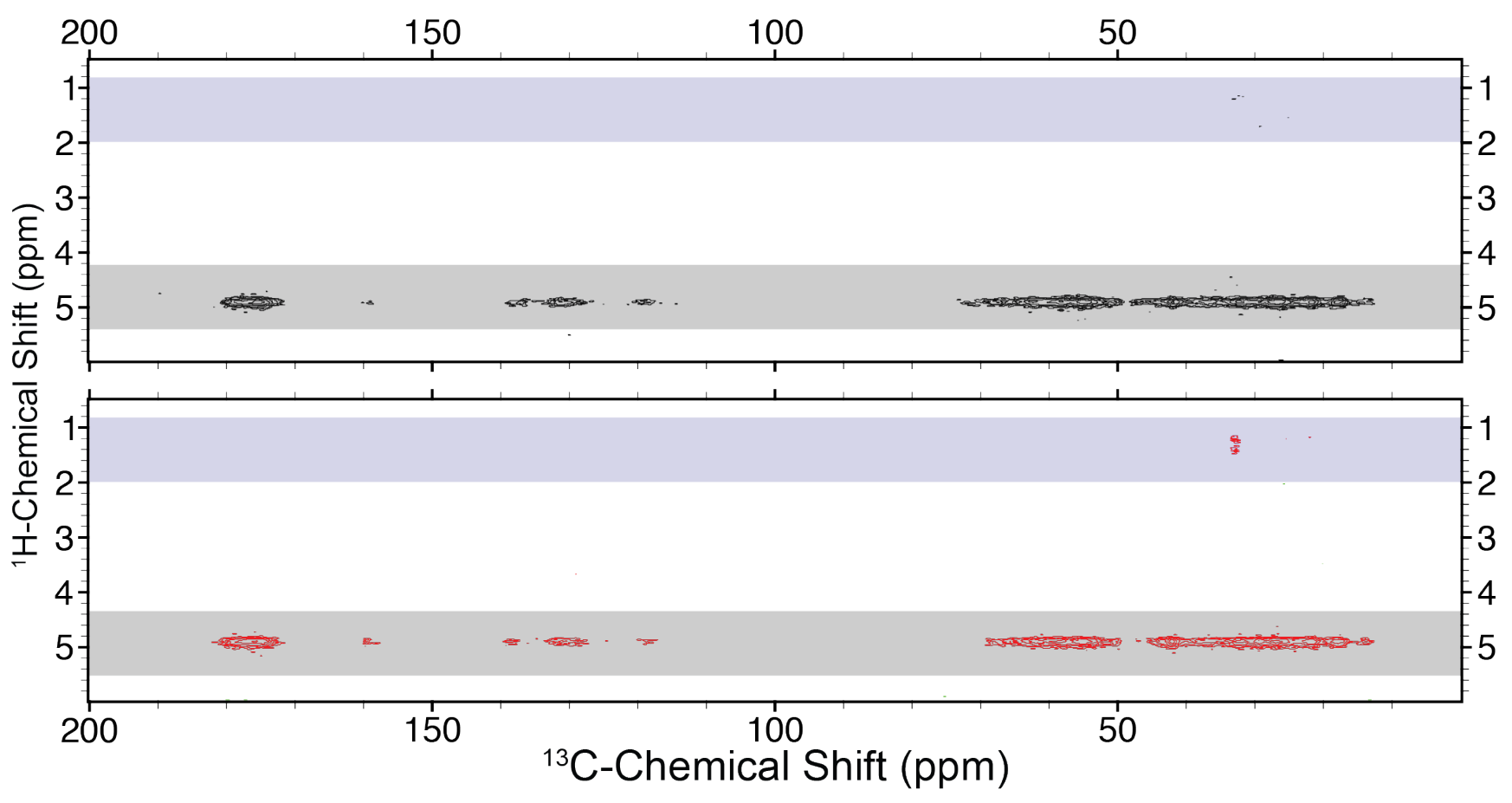

Figure S1: Water-edited ${ }^{1} \mathrm{H}-{ }^{13} \mathrm{C}$ HETCOR spectra of SM (black) and TQ (red) in PE:PG:CL lipids. Region in blue correspond to lipid acyl chain ${ }^{1} \mathrm{H}-{ }^{13} \mathrm{C}$ correlations. Grey region corresponds to protein ${ }^{1} \mathrm{H}-{ }^{13} \mathrm{C}$ correlations that originated from solvent 


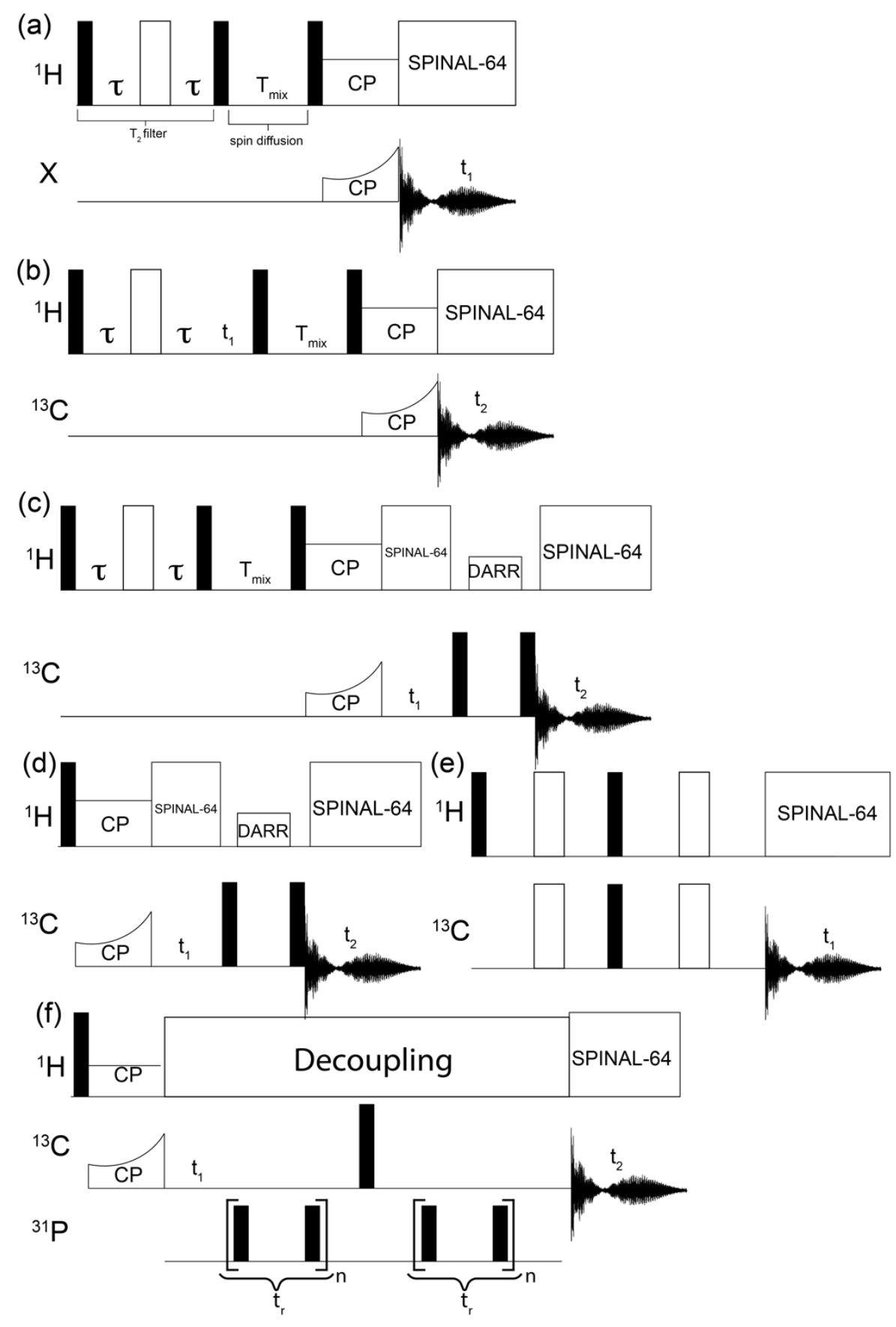

Figure S2: Pulse sequences used. (a) $1 \mathrm{D} \mathrm{H}_{2} \mathrm{O}$-edited ${ }^{1} \mathrm{H}$-buildup for transfer to variable nuclei, (b) $2 \mathrm{D} \mathrm{H} \mathrm{H}_{2} \mathrm{O}$-edited ${ }^{1} \mathrm{H}-{ }^{13} \mathrm{C}$ HETCOR, (c) $2 \mathrm{D} \mathrm{H} \mathrm{H}_{2} \mathrm{O}$-edited ${ }^{13} \mathrm{C}-{ }^{13} \mathrm{C}$ DARR, (d) ${ }^{13} \mathrm{C}-{ }^{13} \mathrm{C}$ DARR, (e) ${ }^{1} \mathrm{H}-{ }^{13} \mathrm{C}$ rINEPT, and (f) ${ }^{13} \mathrm{C}-{ }^{31} \mathrm{P}$ REDOR. 


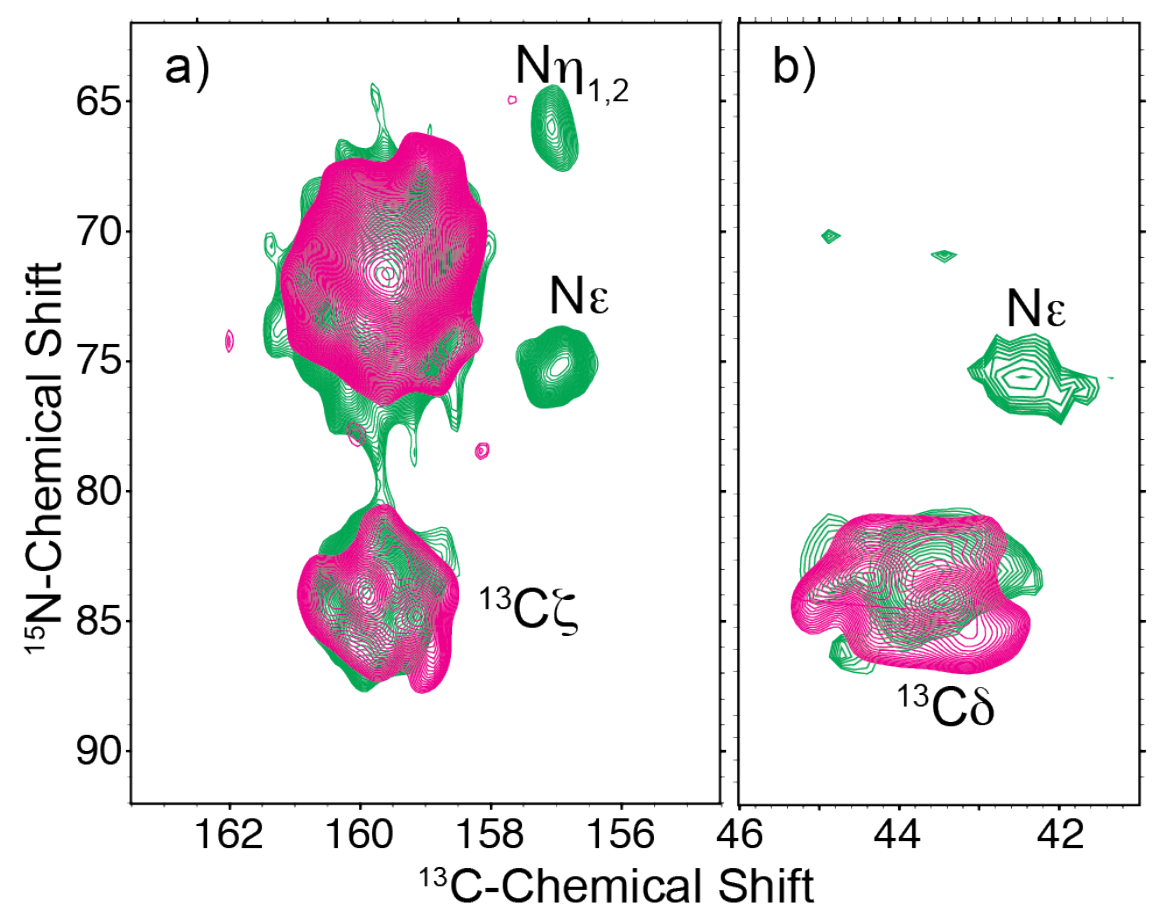

Figure S3: Spectral identification of arginines bound to anionic lipids. a) NcoCX 2D of KirBac1.1 in 3:1 POPE:POPG (w/w) lipid bilayer (green) and POPE bilayer (magenta) allowing for identification of $\mathrm{N}_{11,2}$ and $\mathrm{N} \varepsilon$ outlier peaks. b) $\mathrm{NcaCX} 2 \mathrm{D}$ showing isolated $\mathrm{N} \varepsilon$ peak.

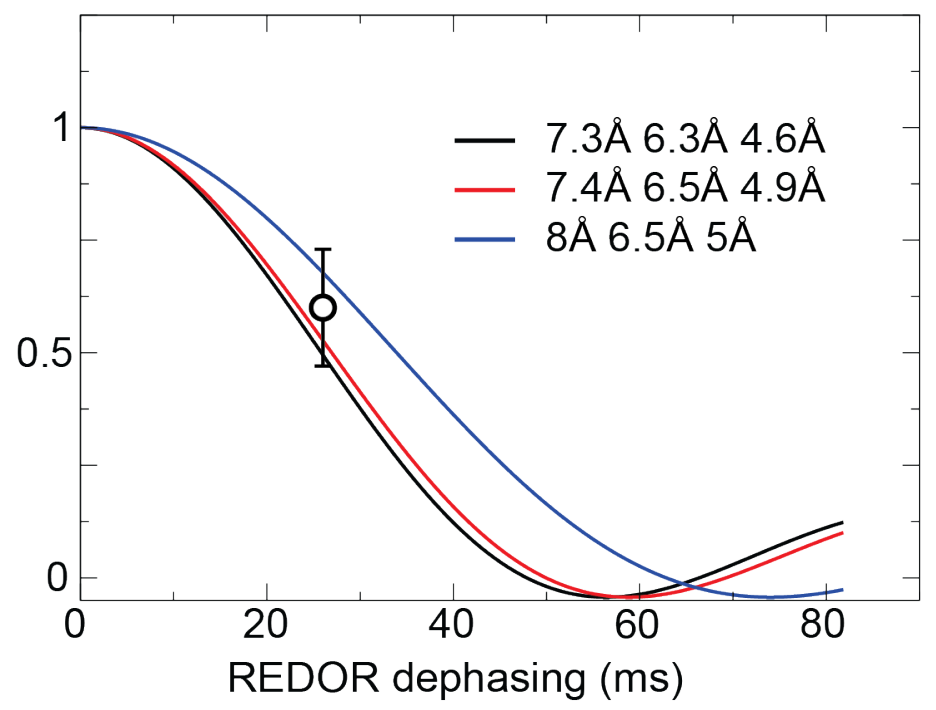

Figure S4: Simulated REDOR dephasing curve via SIMPSON. For all the simulation three carbons and one phosphorus atom has been considered. Longer distance than crystal structure (blue line), distance in crystal structure (red line), and a lower distance than the crystal structure (black line) has been simulated. 


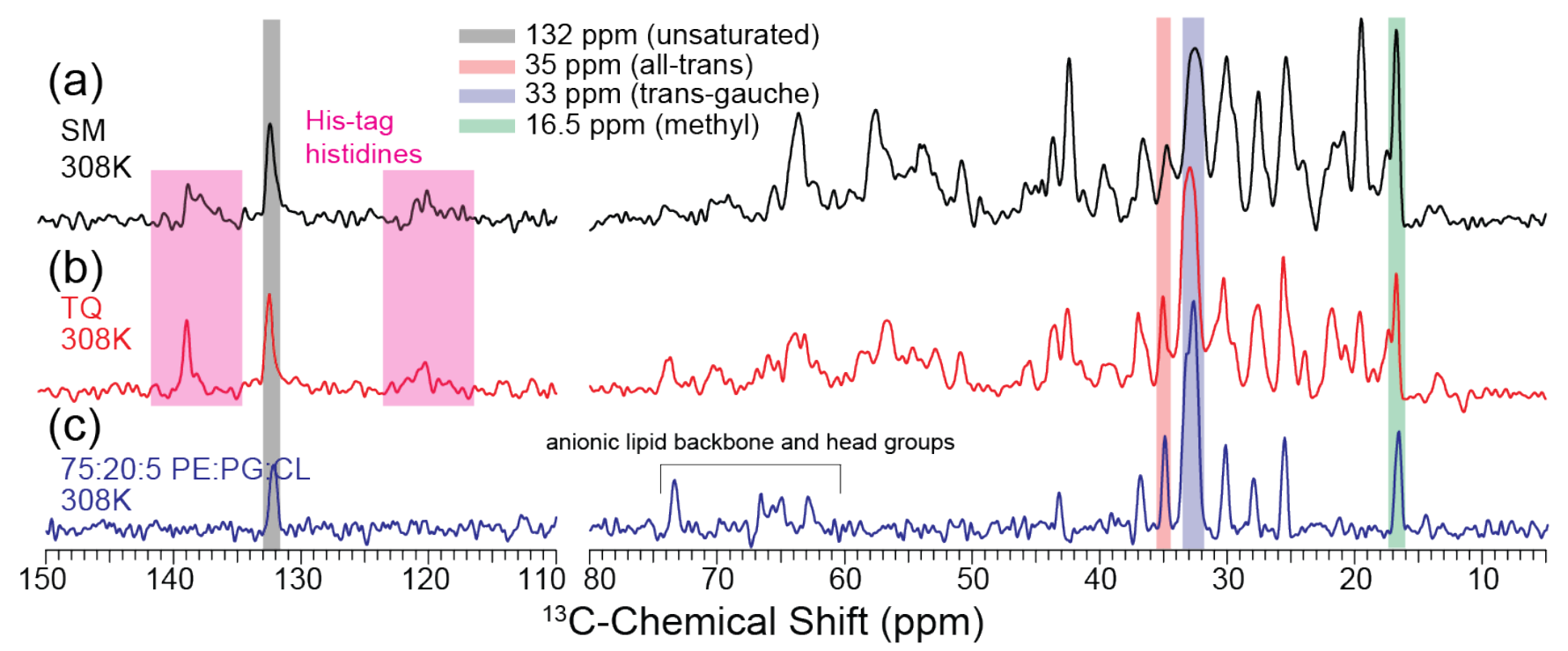

Figure S5: 1D rINEPT spectra of ${ }^{13} \mathrm{C}-{ }^{15} \mathrm{~N}$ KirBac1.1 in proteoliposomes (a) Stability mutant(SM)-KirBac1.1 proteoliposome in natural abundance 75:20:5 PE:PG:CL. (b) Triple Q(TQ)-KirBac1.1 proteoliposome in natural abundance 75:20:5 PE:PG:CL. (c) Natural abundance 75:20:5 PE: PG:CL liposomes without protein. Note: rINEPT polarization filters out the majority of the protein resonances sufficiently enough for $1 \%$ natural abundance lipids to be identified. Resonances corresponding to highly mobile His-tag are identified in magenta. 

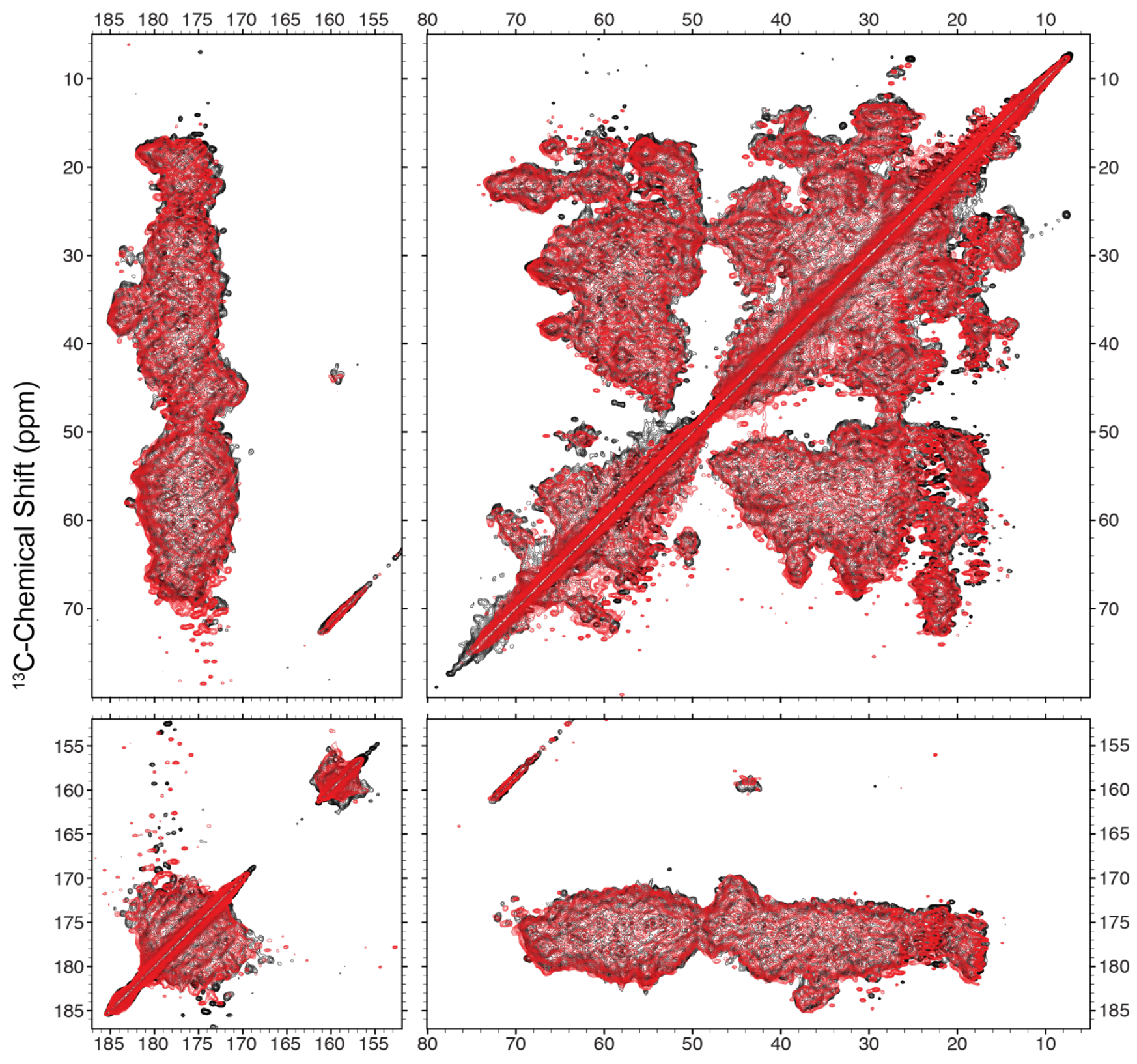

${ }^{13} \mathrm{C}$-Chemical Shift (ppm)

Figure S6: Standard (not water edited) $2 \mathrm{D}{ }^{13} \mathrm{C}-{ }^{13} \mathrm{C}$ DARR spectra of $\mathrm{SM}$ and TQ proteins. The spectrum of the TQ sample (red) is overlaid onto the spectrum of the SM sample (black). Both samples are reconstituted into the same activating PE:PG:CL lipid mixture. 


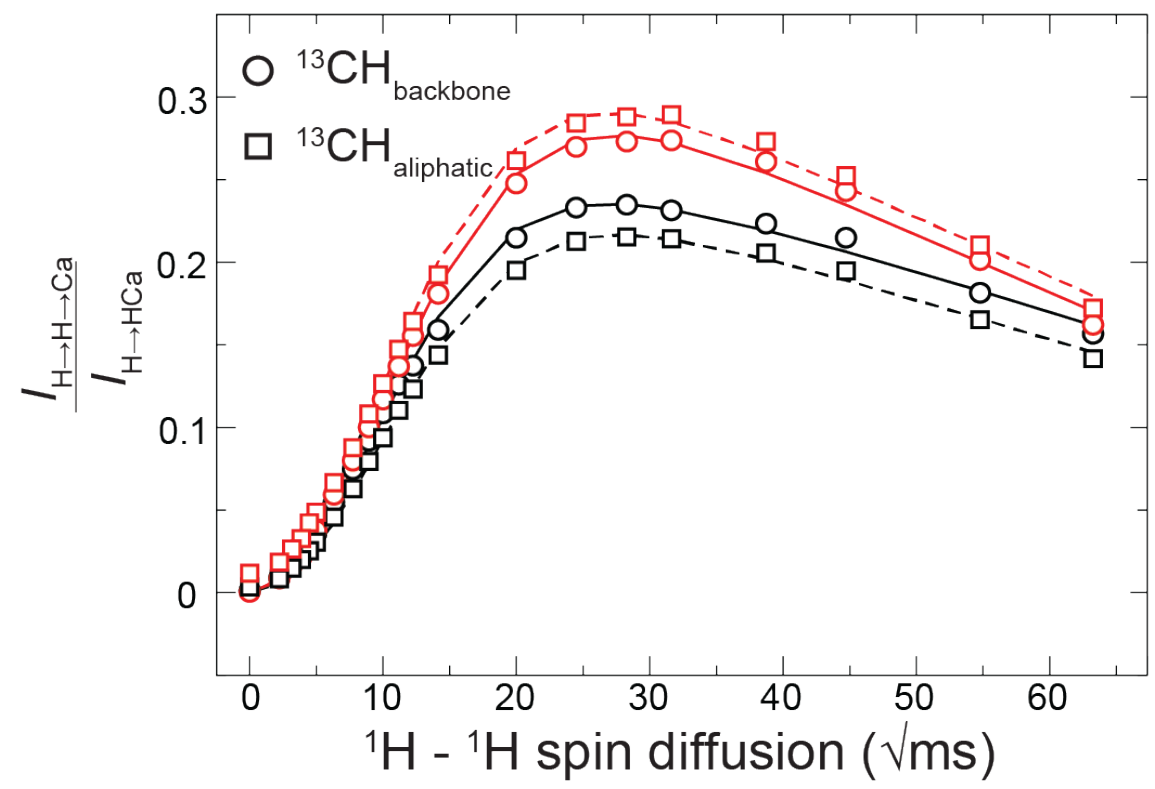

Figure S7: ${ }^{1} \mathrm{H}_{2} \mathrm{O}-{ }^{1} \mathrm{H}_{\text {protein }}$ spin diffusion buildup curves of the bracketed $\mathrm{C} \alpha$ and aliphatic spin systems of SM (black) and TQ(red) proteins. Error bars are within the size of the icons on each point. 


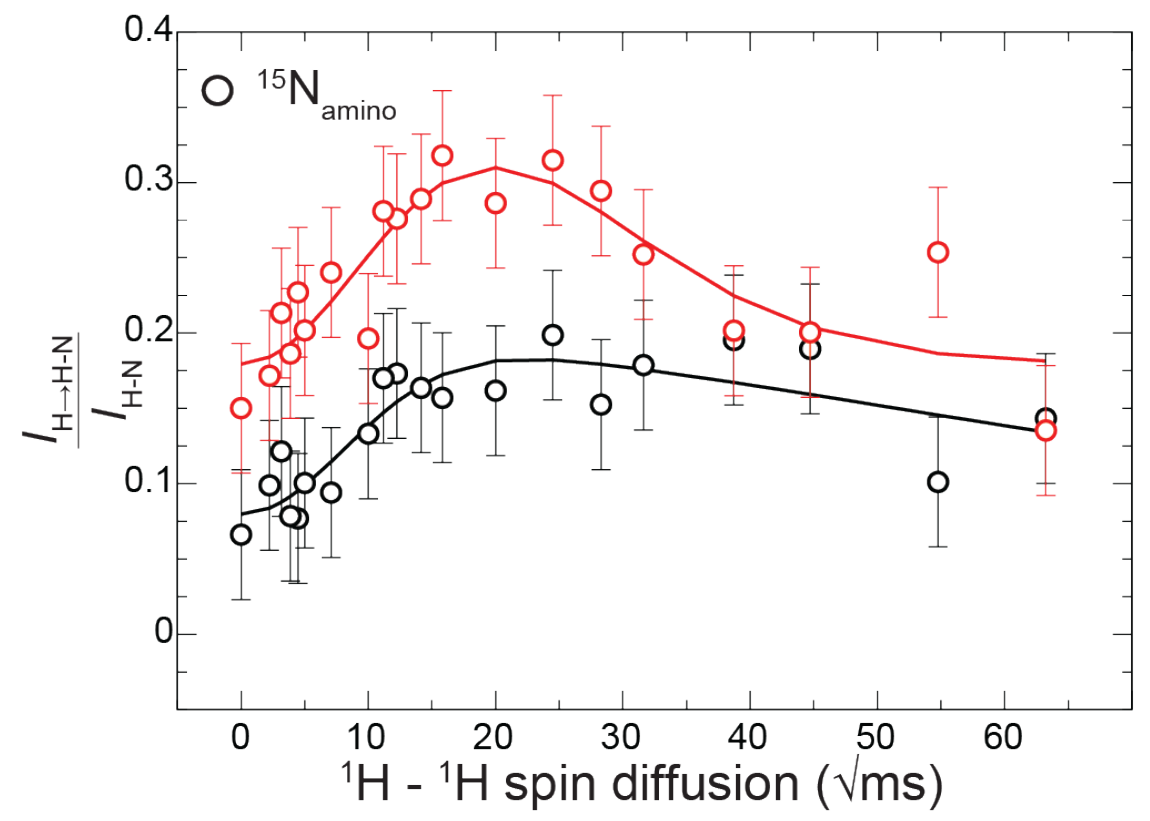

Figure S8: ${ }^{1} \mathrm{H}_{2} \mathrm{O}-{ }^{1} \mathrm{H}_{\text {protein }}$ spin diffusion buildup curves of the bracketed lysine sidechain amino group spin systems for SM (black) and TQ(red) samples. Fitted values of the lysine amino group buildup are closely representative of equation (3) with the addition of a corrective term $M_{p}(0)$ to the end of the equation to represent polarization that survived the $T_{2}$ tilter on the terminal amino group. 


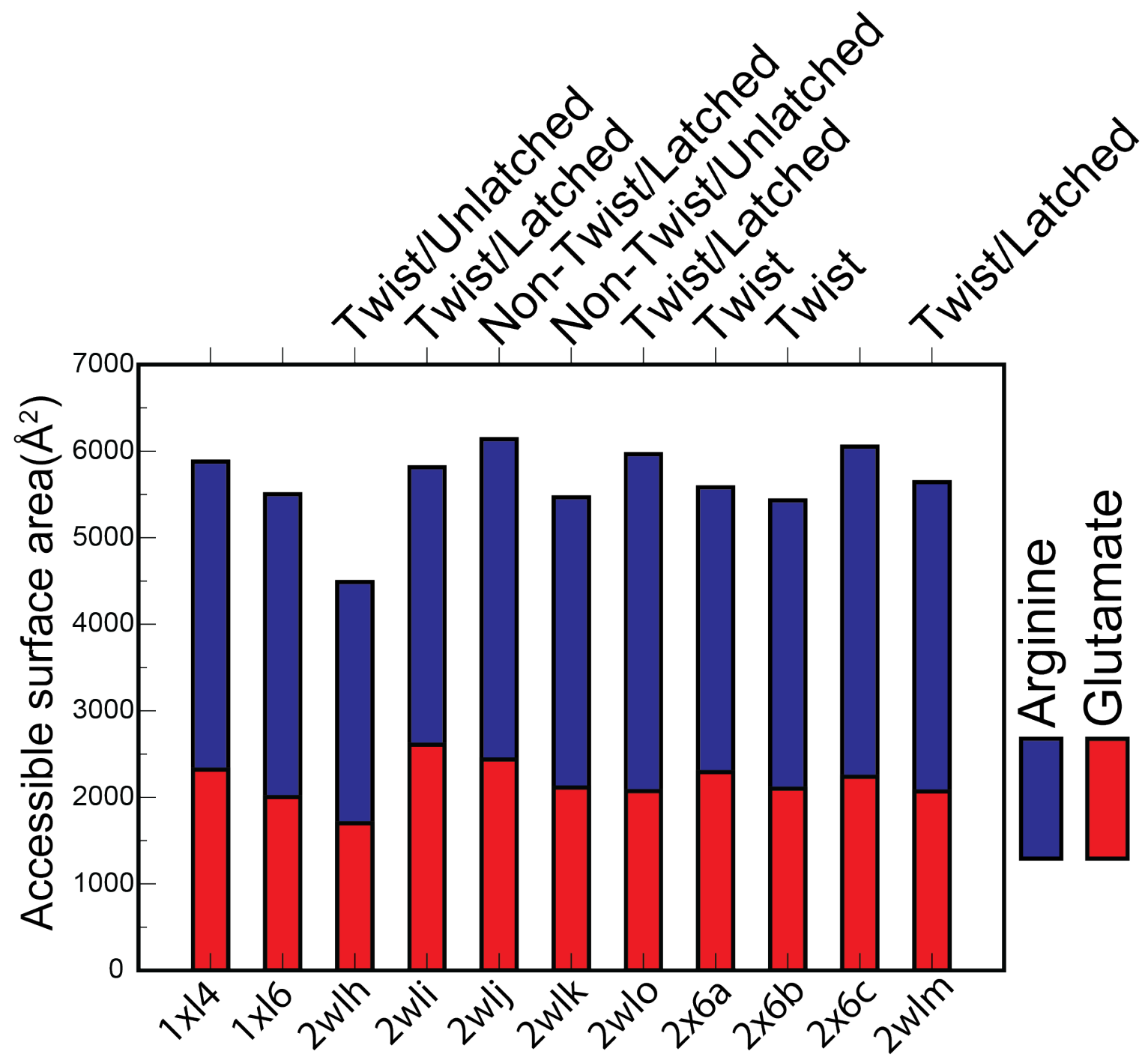

Figure S9: Exposed surface area calculations for arginine and glutamate residues in several KirBac3.1 crystal structures. The observed trend indicates the active "twist/unlatched" state (2wh) has less exposure for these residues than the inactive "non-twist/latched" structures and their variations. While the activation gate is closed for all these structures, it is possible the conformation of the c-terminus of the $2 \mathrm{wlh}$ structure is similar to the open-activated conformation observed in activating lipid bilayers. 


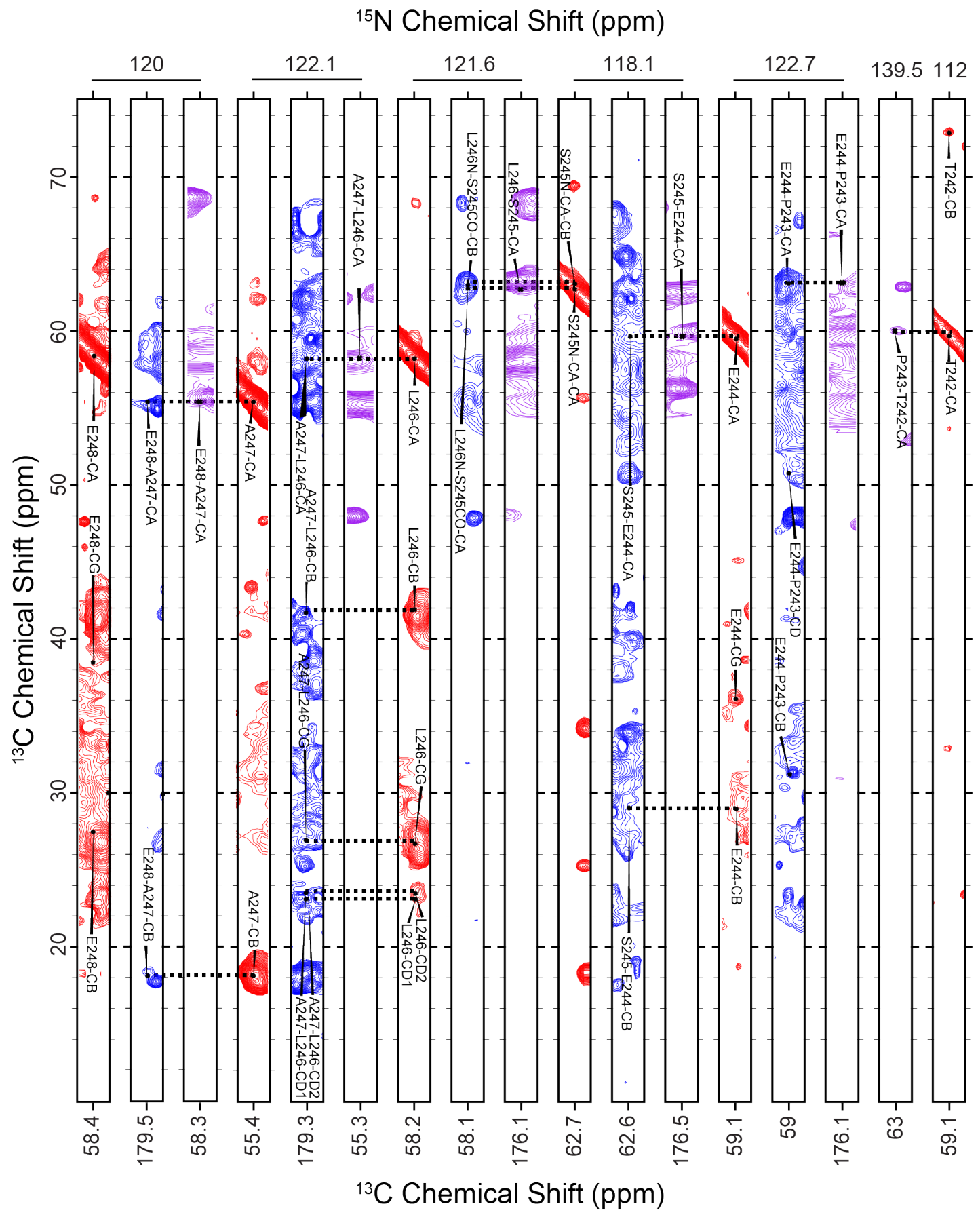

Fig. S10: Strip plot of 3D assignments for residues T242 to E248 of SM KirBac1.1 in POPC lipid bilayers. NCACX (red), CANcoCA (purple), and NCOCX (blue) spectra were used. 


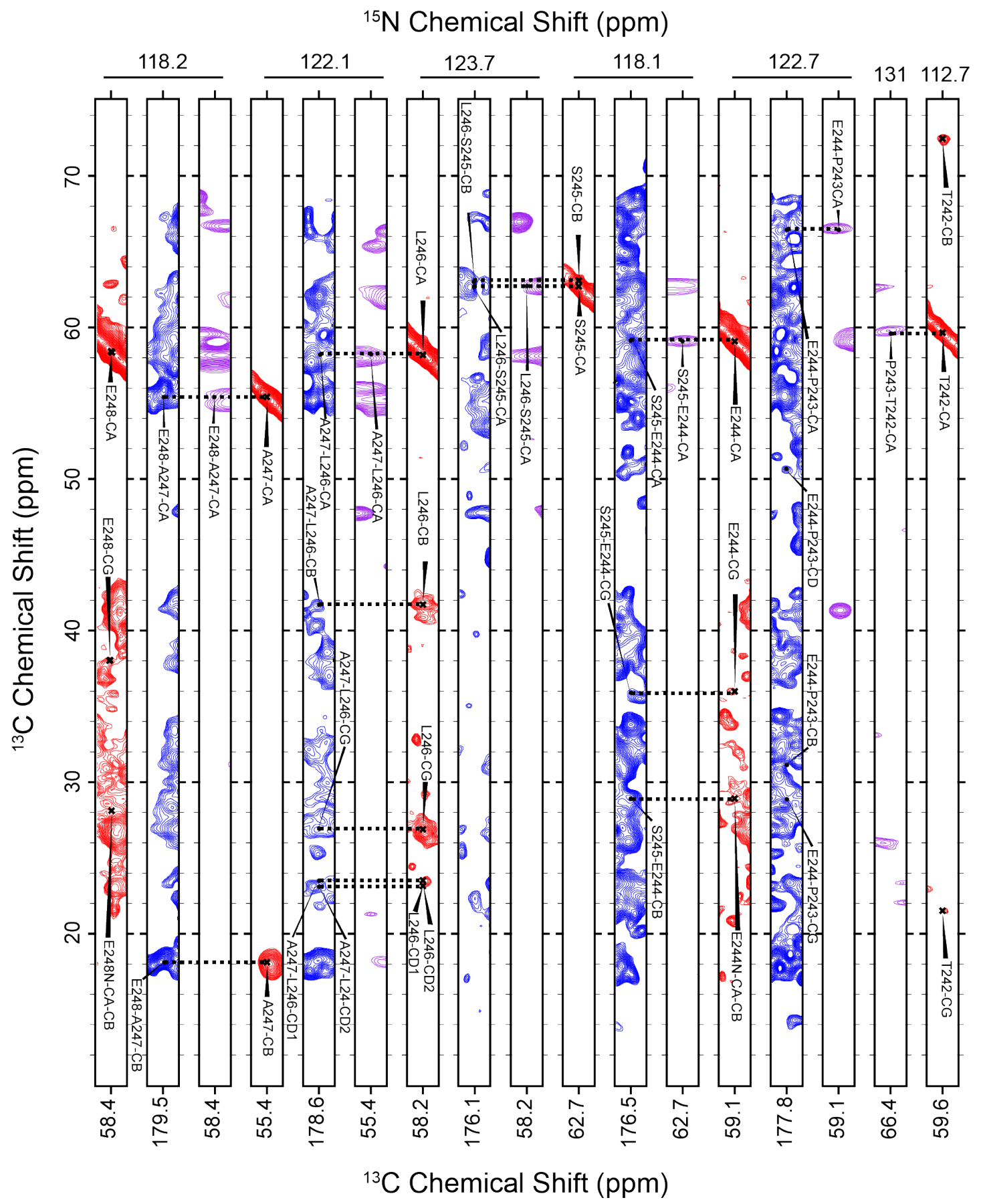

Fig. S11: Strip plot of 3D assignments for residues T242 to E248 of SM KirBac1.1 in POPC:POPG (3:2) w/w lipid bilayers. NCACX (red), CANcoCA (purple), and NCOCX (blue) spectra were used. 


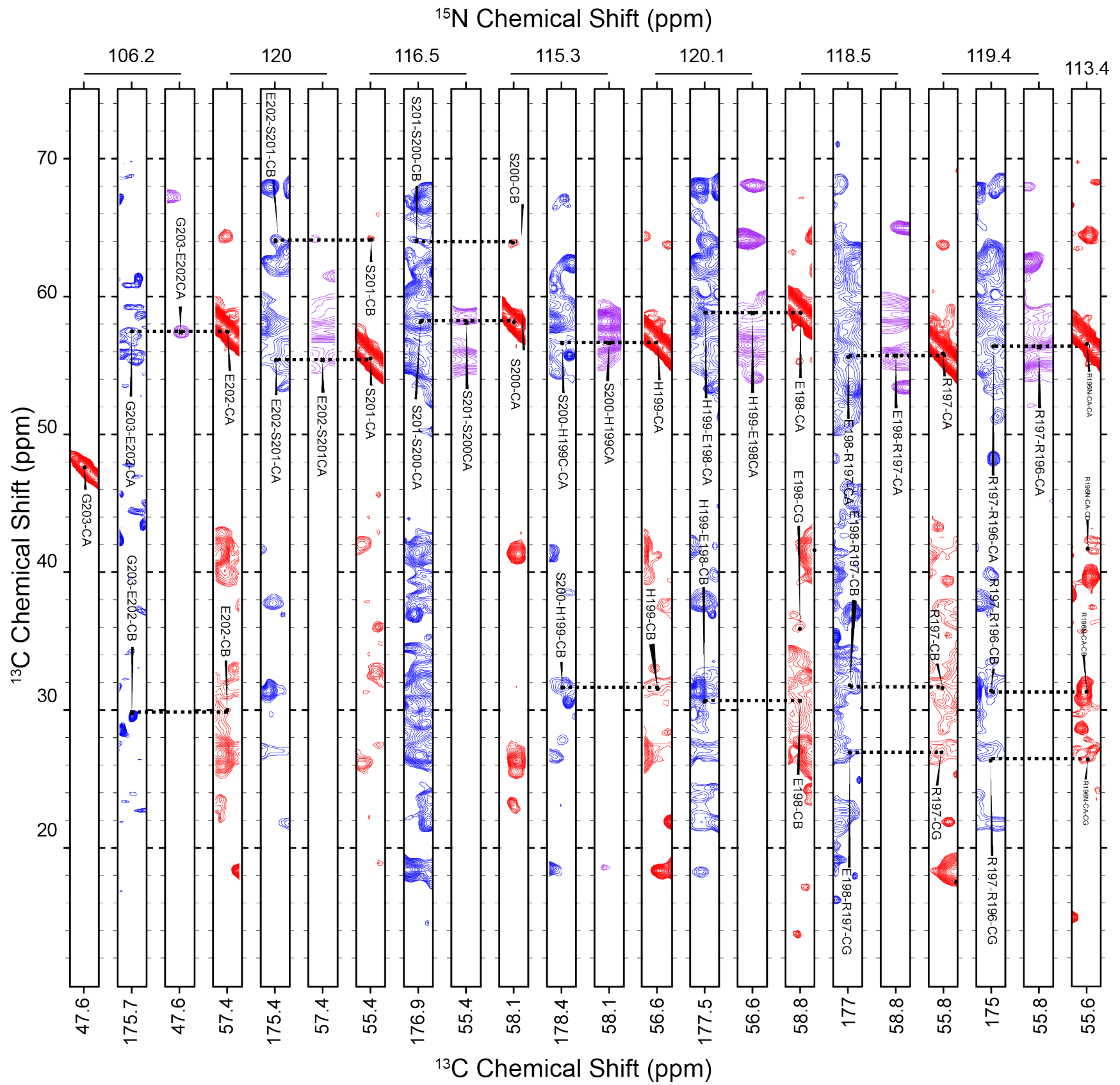

Fig. S12: Strip plot of 3D assignments for residues R196 to G203 of SM KirBac1.1 in POPC lipid bilayers. NCACX (red), CANcoCA (purple), and NCOCX (blue) spectra were used. 


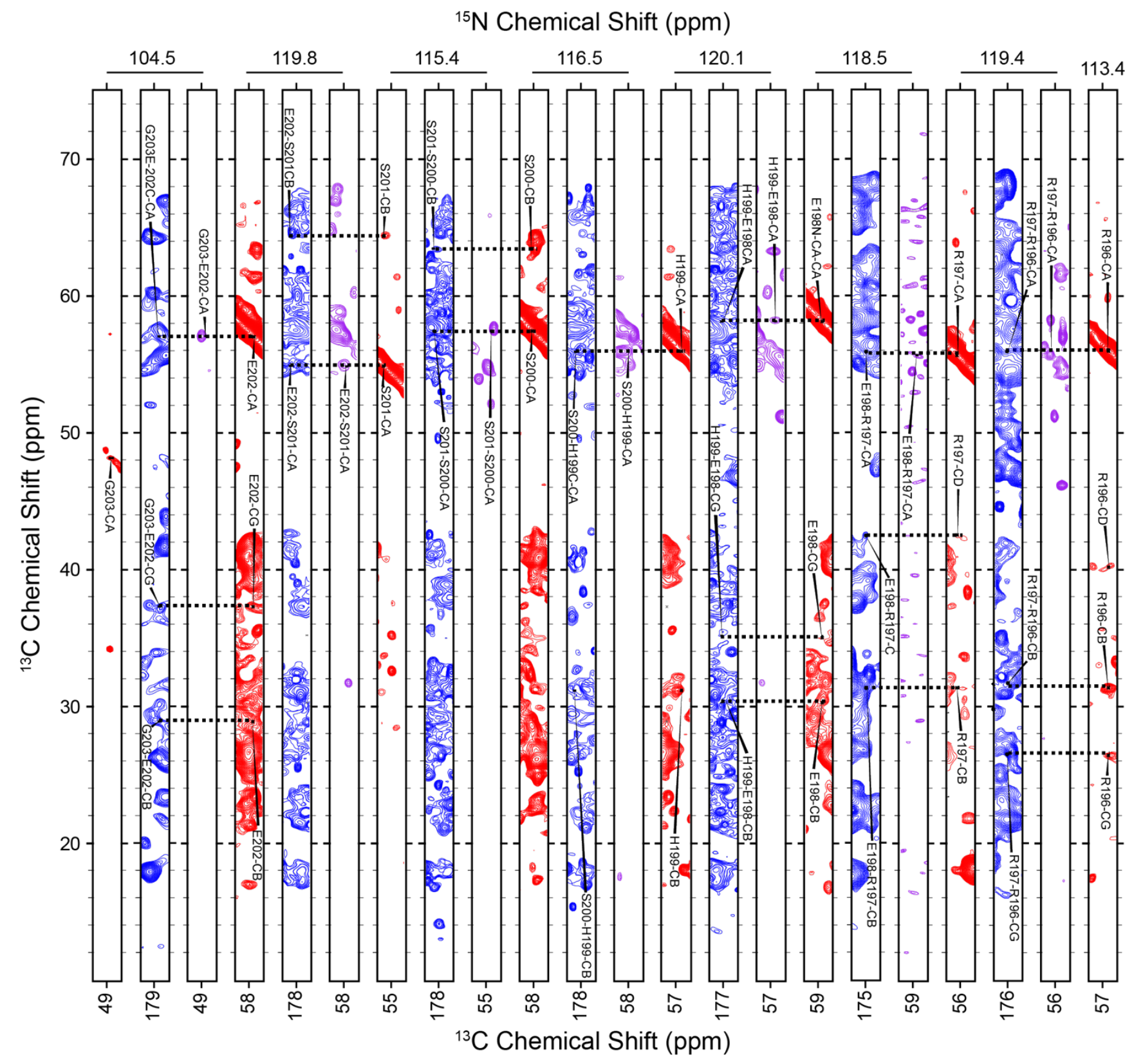

Fig. S13: Strip plot of 3D assignments for residues R196 to G203 of SM KirBac1.1 a in POPC:POPG (3:2) w/w lipid bilayer. NCACX (red), CANcoCA (purple), and NCOCX (blue) spectra were used. 


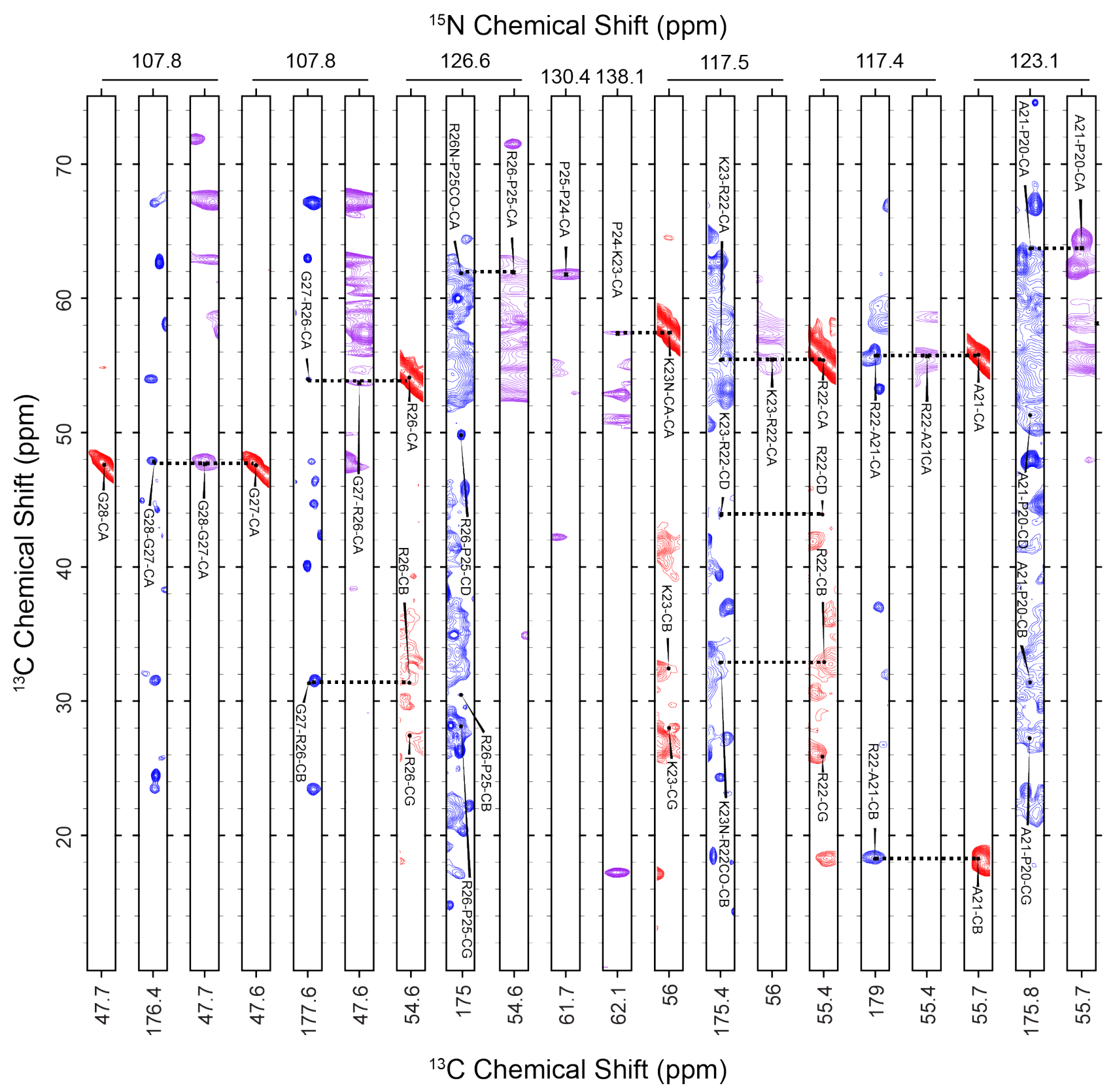

Fig. S14: Strip plot of 3D assignments for residues P20 to R28 of SM KirBac1.1 in POPC lipid bilayers. NCACX (red), CANcoCA (purple), and NCOCX (blue) spectra were used. 


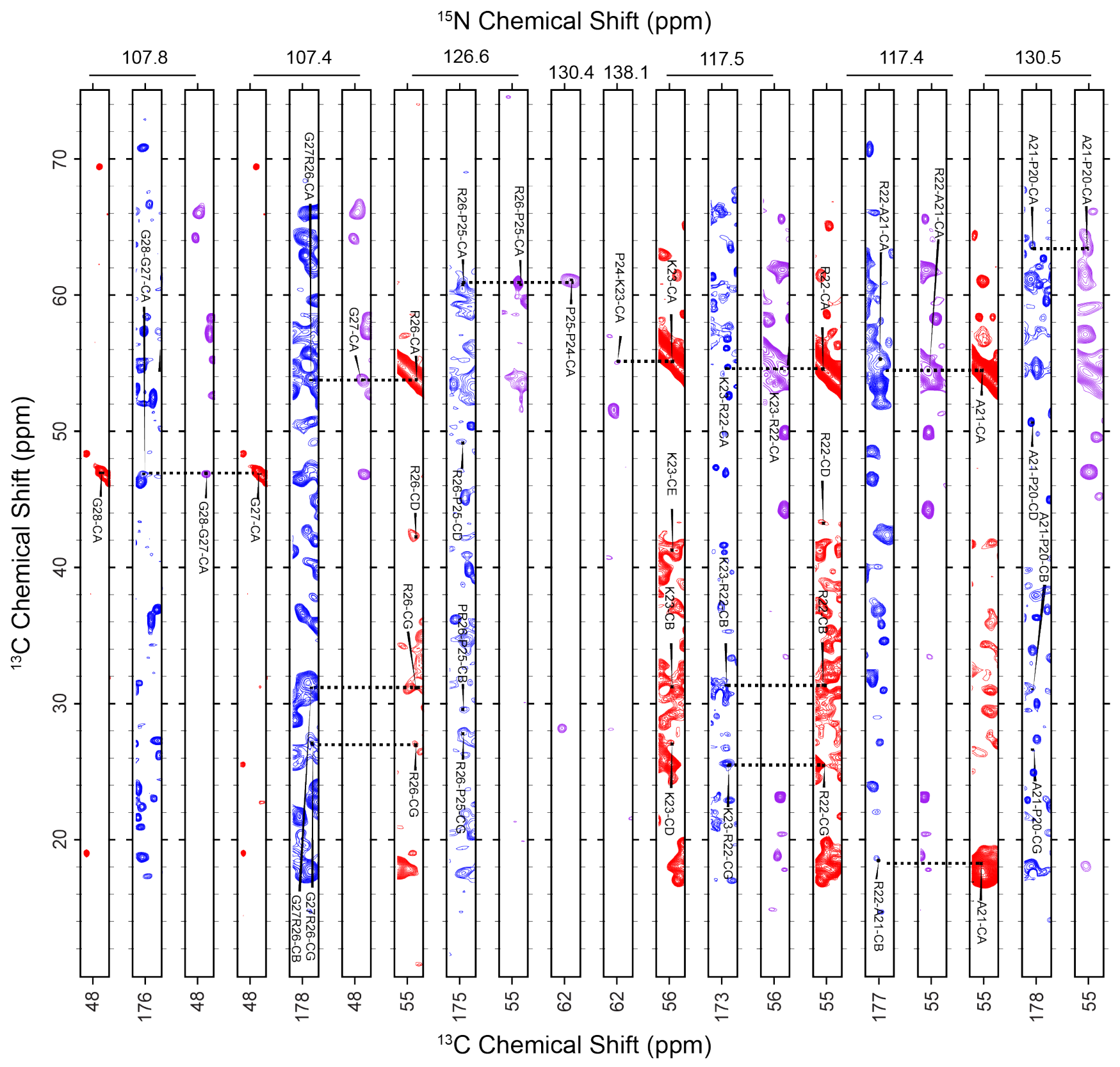

Fig. S15: Strip plot of 3D assignments for residues R28 to P20 of SM KirBac1.1 in 3:2 POPC:POPG (w/w) lipid bilayers. NCACX (red), CANcoCA (purple), and NCOCX (blue) spectra were used. 


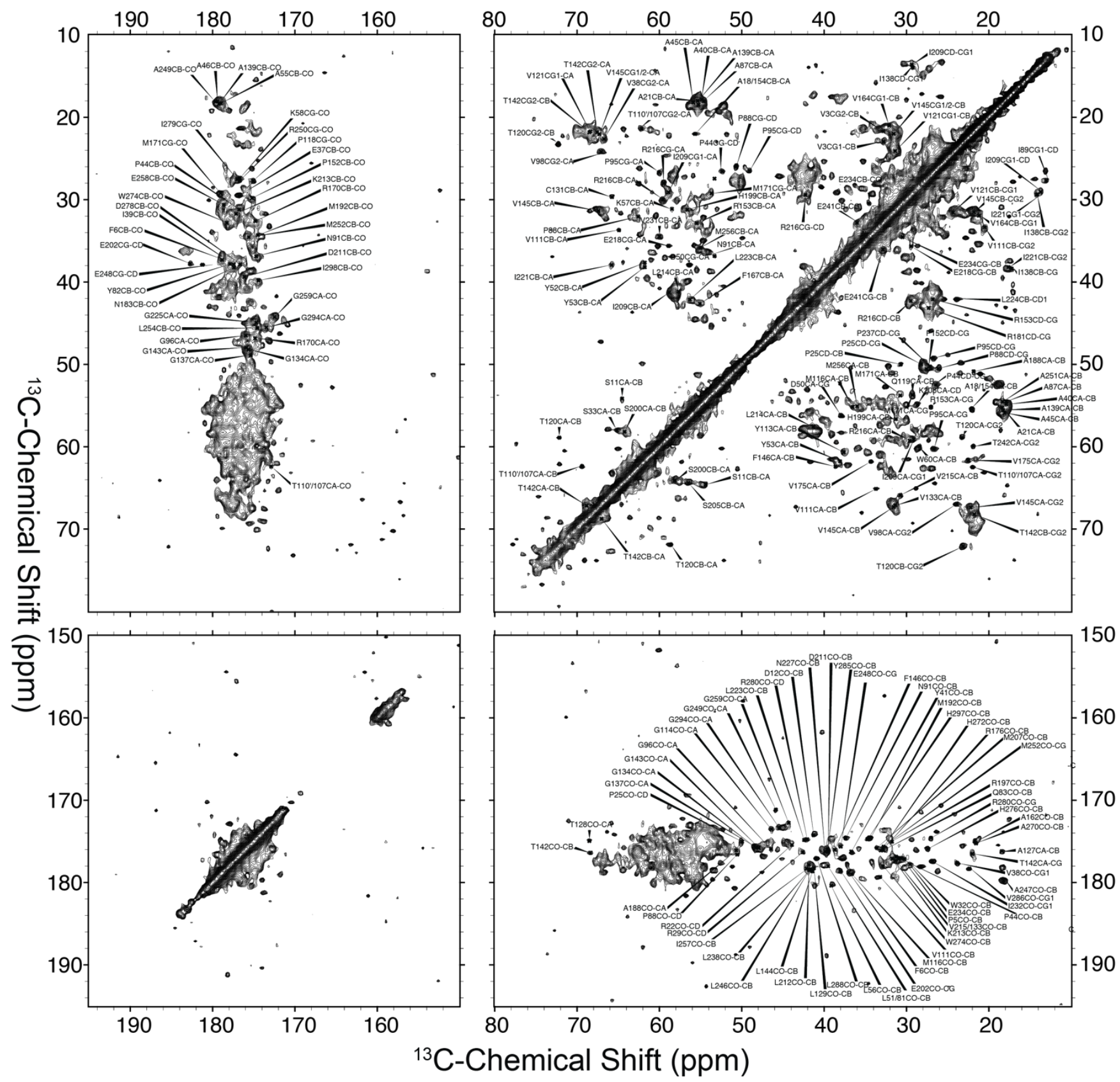

Figure S16: Assigned water-edited ${ }^{13} \mathrm{C}-{ }^{13} \mathrm{C}$ correlation spectrum of $\mathrm{U}-{ }^{13} \mathrm{C},{ }^{15} \mathrm{~N}$ KirBac1.1 (SM) in the PE:PG:CL lipid mixture with $5 \mathrm{~ms}$ of ${ }^{1} \mathrm{H}_{\text {mix. }}$. 


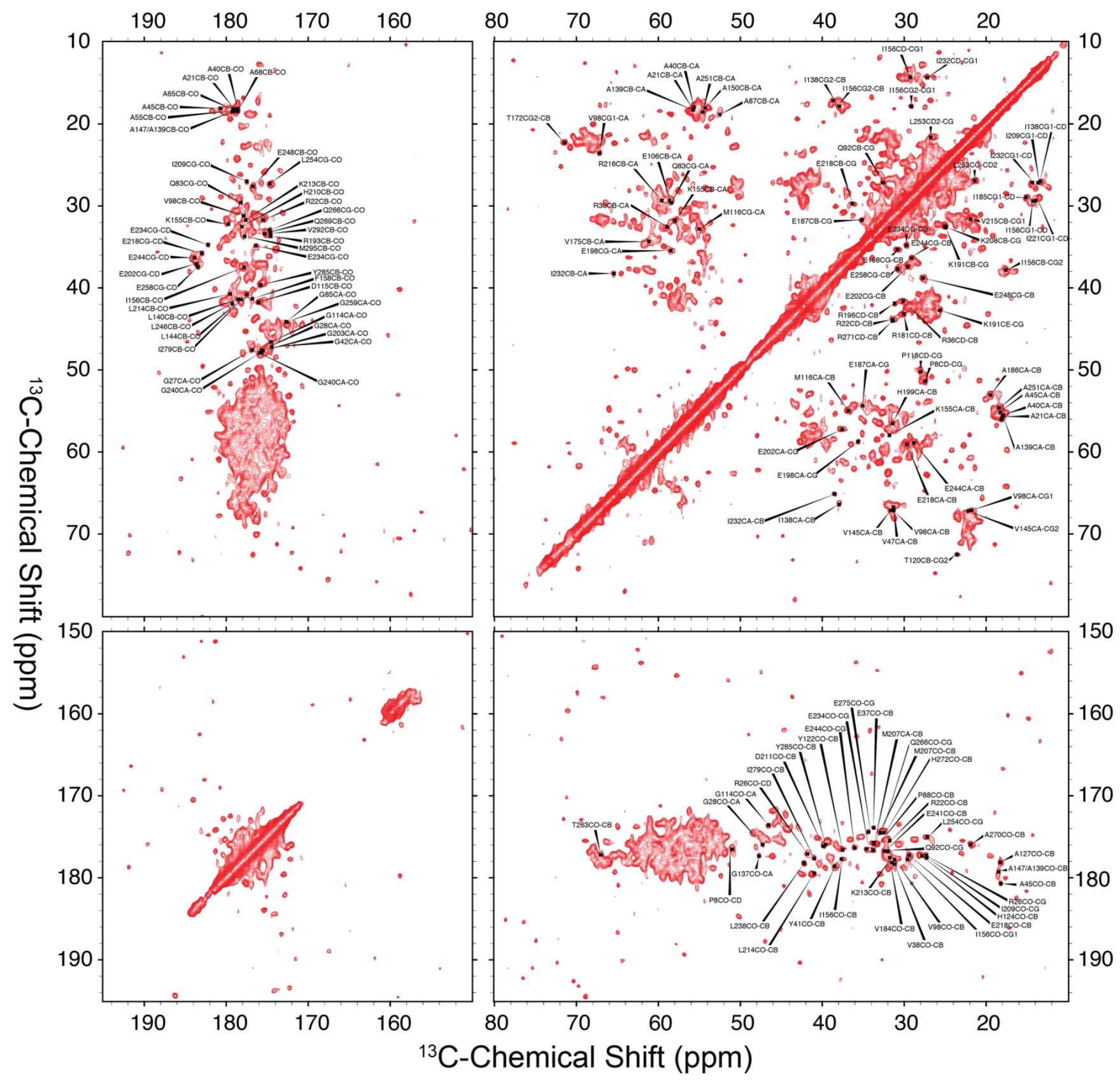

Figure S17: Assigned water-edited ${ }^{13} \mathrm{C}-{ }^{13} \mathrm{C}$ correlation spectrum of $\mathrm{U}-{ }^{13} \mathrm{C},{ }^{15} \mathrm{~N}$ KirBac1.1 (R49/151/153Q) in the PE:PG:CL lipid mixture using $5 \mathrm{~ms}$ of ${ }^{1} \mathrm{H}_{\text {mix. }}$. 


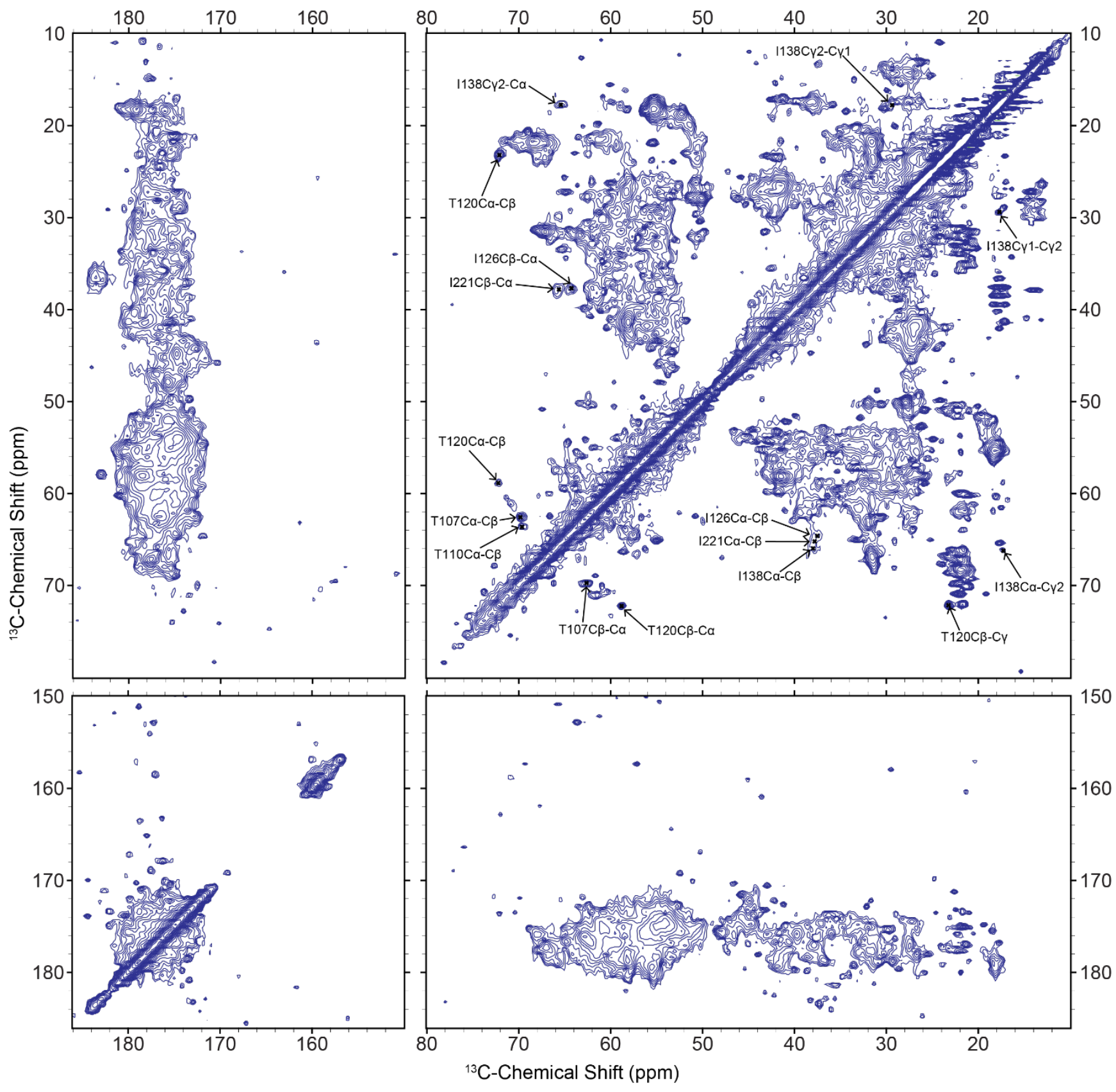

Figure S18: Water-edited 2D ${ }^{13} \mathrm{C}-{ }^{13} \mathrm{C}$ DARR experiment on the SM PE:PG:CL sample implementing $12 \mathrm{~ms}$ of ${ }^{1} \mathrm{H}_{\text {mix }}$. Residues further from the proposed water-protein interface are observed, namely 1126. 
Table S1: List of chemical shifts for the water-edited ${ }^{13} \mathrm{C}-{ }^{13} \mathrm{C} 2 \mathrm{D}$ spectrum assignments of SM KirBac1.1 in PE:PG:CL bilayers. Residues in blue were more exposed than in TQ.

\begin{tabular}{|l|l|l|l|l|l|l|}
\hline Residue & C & CA & CB & CG1 & CG2 & CD1 \\
\hline V3 & & & 32.7 & 22.9 & 21.6 & \\
\hline P5 & 177.1 & & 30.6 & & & \\
\hline F6 & 177.1 & & 37.2 & & & \\
\hline S11 & & 54.3 & 64.5 & & & \\
\hline D12 & 174.217 & & 41.266 & & & \\
\hline Q16 & & & 29.0 & 34.2 & & \\
\hline A18/154 & & 55.6 & 22.0 & & & \\
\hline S19 & & 64.5 & 57.8 & & & \\
\hline A21 & & 55.2 & 18.4 & & & \\
\hline R22 & 175.4 & 43.9 & & & & \\
\hline P25 & 175.1 & 50.0 & 30.7 & 28.2 & & \\
\hline R29 & 176.2 & & & & & 42.5 \\
\hline W32 & 177.8 & & 29.5 & & & \\
\hline S33 & & 58.0 & 65.2 & & & \\
\hline E37 & 176.8 & & 29.5 & & & \\
\hline V38 & & 66.7 & & 23.8 & 22.6 & \\
\hline I39 & 177.5 & & 37.8 & & & \\
\hline A40 & & 54.9 & 17.8 & & & \\
\hline Y41 & 176.2 & & 36.7 & & & \\
\hline P44 & 176.8 & & & 26.5 & & 52.4 \\
\hline A45 & & 55.9 & 18.2 & & & \\
\hline A46 & 179.4 & & 18.1 & & & \\
\hline D50 & & 56.3 & 37.9 & & & \\
\hline L51/81 & 178.0 & & 39.5 & & & \\
\hline Y52 & & 61.8 & 37.7 & & & \\
\hline Y53 & & 61.8 & 38.1 & & & \\
\hline A55 & 179.0 & & 18.3 & & & \\
\hline L56 & 180.4 & & 39.1 & & & \\
\hline K57 & 176.7 & 58.5 & 31.1 & 27.4 & & \\
\hline W60 & & 60.1 & 28.4 & & & \\
\hline Y82 & 177.9 & & 37.8 & & & \\
\hline Q83 & 176.1 & & 32.8 & & & \\
\hline A87 & & 54.6 & 17.9 & & & \\
\hline P88 & & 62.6 & 32.1 & 50.6 & & 26.0 \\
\hline I89 & & & 27.7 & & 13.1 \\
\hline
\end{tabular}




\begin{tabular}{|l|l|l|l|l|l|l|}
\hline N91 & 174.6 & 53.9 & 36.5 & & & \\
\hline P95 & & 60.2 & & 26.7 & 49.1 & \\
\hline G96 & 175.9 & 46.5 & & & & \\
\hline V98 & & 67.0 & & & 24.0 & \\
\hline T110'/T107 & 172.9 & 62.3 & 69.4 & & 21.7 & \\
\hline V111 & 179.3 & 65.0 & 33.5 & & 20.5 & \\
\hline G112 & 175.6 & 48.1 & & & & \\
\hline Y113 & 178.0 & 60.7 & 37.6 & & & \\
\hline G114 & 173.4 & 46.4 & & & & \\
\hline M116 & 179.0 & 55.2 & 36.6 & & & \\
\hline Q119 & & 53.7 & 29.3 & & 23.2 & \\
\hline P118 & 175.1 & & & 27.7 & & \\
\hline Q119 & & 53.7 & 29.3 & & & \\
\hline T120 & & 58.8 & 72.1 & & 23.2 & \\
\hline V121 & & 68.4 & 31.5 & 23.4 & & \\
\hline A127 & 176.2 & & 18.4 & & & \\
\hline T128 & 174.9 & & 68.5 & & & \\
\hline L129 & 178.3 & & 41.3 & & & \\
\hline C131 & & 65.7 & 29.7 & & & \\
\hline V133 & & 67.1 & 31.4 & & & \\
\hline G134 & 175.8 & 48.2 & & & & \\
\hline G137 & 175.5 & 48.5 & & & 17.4 & \\
\hline I138 & & & 38.4 & 29.3 & 17.3 & 14.1 \\
\hline A139 & 179.2 & 55.4 & 18.2 & & 21.8 & \\
\hline T142 & 176.5 & 67.2 & 68.5 & & 21.9 & \\
\hline G143 & 175.9 & 47.9 & & & & \\
\hline L144 & 178.6 & & 41.4 & & & \\
\hline V145 & & 67.3 & 31.5 & & 22.0 & \\
\hline F146 & 176.0 & 62.4 & 38.7 & & & \\
\hline P152 & 175.2 & & 29.8 & 27.6 & & \\
\hline R153 & & 55.3 & 32.9 & 26.9 & & 42.1 \\
\hline A154 & & 55.6 & 22.0 & 26.9 & & \\
\hline A162 & 174.9 & & 21.7 & & & \\
\hline V164 & & & 32.0 & 21.1 & & \\
\hline F167 & & 55.1 & 42.6 & & & \\
\hline M171 & 179.0 & 53.7 & 30.8 & 29.2 & & 43.2 \\
\hline N183 & 177.4 & & 38.2 & & & \\
\hline A188 & 176.1 & 50.8 & 21.9 & & & \\
\hline M192 & 174.5 & & 34.3 & & & \\
\hline
\end{tabular}




\begin{tabular}{|l|l|l|l|l|l|l|}
\hline R197 & 175.0 & & 31.8 & & & \\
\hline H199 & & 56.6 & 31.3 & & & \\
\hline S200 & & 58.2 & 64.2 & & & \\
\hline E202 & 178.6 & & & 37.9 & 178.6 & \\
\hline S205 & & 56.5 & 64.4 & & & \\
\hline M207 & 175.8 & & 33.6 & & & \\
\hline K208 & & 54.9 & & & 28.7 & \\
\hline I209 & & 58.9 & 41.3 & 29.1 & & 13.6 \\
\hline D211 & 176.2 & & 39.5 & & & \\
\hline L212 & 177.8 & & 41.8 & & & \\
\hline K213 & 177.1 & & 31.7 & & & \\
\hline L214 & & 57.6 & 41.3 & & & \\
\hline V215 & 177.3 & 65.9 & 30.7 & & & \\
\hline R216 & & 59.4 & 29.7 & 28.7 & & 42.3 \\
\hline E218 & & 58.9 & 29.4 & 35.6 & & \\
\hline I221 & & 65.8 & 38.1 & 29.4 & 17.6 & 14.2 \\
\hline L223 & 174.8 & 56.3 & 42.1 & & & \\
\hline L224 & & & 42.0 & & & 23.9 \\
\hline G225 & 174.7 & 44.9 & & & & \\
\hline N227 & 176.2 & & 39.9 & & & \\
\hline V231 & & 60.0 & 34.5 & & & \\
\hline I232 & 177.4 & & & 26.9 & & \\
\hline E234 & 177.1 & & 30.4 & 34.6 & & \\
\hline P237 & & & & 27.1 & & 50.2 \\
\hline L238 & 178.4 & & 41.6 & & & \\
\hline E241 & & & 32.8 & 36.0 & & \\
\hline T242 & & 59.9 & & & 21.9 & \\
\hline E248 & 175.6 & & & 37.9 & & 181.2 \\
\hline G249 & 171.1 & 45.8 & & & & \\
\hline R250 & 176.7 & & & 27.7 & & \\
\hline A251 & & 54.6 & 18.3 & & & 44.0 \\
\hline M252 & 175.6 & & 34.6 & 32.8 & & \\
\hline L254 & 174.6 & & 45.6 & & & \\
\hline M256 & & 55.1 & 35.9 & & & \\
\hline I257 258 & & 42.1 & & & \\
\hline G259 & 176.6 & & 21.6 & & & \\
\hline A270 & & 33.1 & & & \\
\hline H272 & & & & & \\
\hline
\end{tabular}




\begin{tabular}{|l|l|l|l|l|l|l|}
\hline W274 & 178.1 & & 32.8 & & & \\
\hline H276 & 175.9 & & 27.3 & & & \\
\hline D278 & 176.6 & & 37.8 & & & \\
\hline I279 & 177.0 & & & & 27.5 & \\
\hline R280 & 174.7 & & & 27.0 & & 42.0 \\
\hline Y285 & 175.9 & & 39.6 & & & \\
\hline V286 & 178.3 & & & 22.4 & & \\
\hline L288 & 177.1 & & 41.0 & & & \\
\hline G294 & 173.4 & 45.5 & & & & \\
\hline H297 & 174.7 & & 34.7 & & & \\
\hline I298 & 174.5 & & 39.8 & & & \\
\hline
\end{tabular}


Table S2: List of chemical shifts for the water-edited ${ }^{13} \mathrm{C}-{ }^{13} \mathrm{C} 2 \mathrm{D}$ spectrum of $\mathrm{TQ}$ (R49/151/153Q) KirBac1.1 in PE:PG:CL bilayers. Residues with greater water exposure than SM are in red.

\begin{tabular}{|l|l|l|l|l|l|l|l|l|}
\hline Residue & C & CA & CB & CG1 & CG2 & CD1 & CD2 & CE \\
\hline P8 & 176.5 & & & 27.4 & & 51.2 & & \\
\hline A21 & 179.0 & 55.7 & 18.2 & & & & & \\
\hline R22 & 175.5 & & 31.6 & & & 43.9 & & \\
\hline R26 & 177.2 & & & 27.3 & & 41.8 & & \\
\hline G27 & 176.9 & 47.6 & & & & & & \\
\hline G28 & 175.8 & 47.4 & & & & & & \\
\hline R30 & & 58.9 & 32.5 & & & & & \\
\hline R36 & & & 30.1 & & & 41.6 & & \\
\hline E37 & 173.9 & & 33.7 & & & & & \\
\hline V38 & 178.3 & & 31.2 & & & & & \\
\hline A40 & 178.6 & 55.6 & 18.0 & & & & & \\
\hline Y41 & 178.6 & & 38.5 & & & & & \\
\hline G42 & 174.4 & 47.2 & & & & & & \\
\hline A45 & 180.7 & 55.2 & 18.2 & & & & & \\
\hline V47 & & 66.7 & 31.3 & & & & & \\
\hline A55 & 179.0 & & 18.4 & & & & & \\
\hline A65 & 179.2 & & 18.2 & & & & & \\
\hline A68 & 178.6 & & 18.5 & & & & & \\
\hline Q83 & 178.2 & 58.4 & & 29.6 & & & & \\
\hline G85 & 172.7 & 44.1 & & & & & & \\
\hline A87 & & 52.5 & 18.9 & & & & & \\
\hline P88 & 176.6 & & 33.8 & & & & & \\
\hline Q92 & 176.8 & & 27.1 & 32.3 & & & & \\
\hline V98 & 177.8 & 67.2 & 31.2 & 22.7 & & & & \\
\hline E106 & & 58.6 & 29.3 & & & & & \\
\hline D115 & 176.1 & 41.7 & & & & & & \\
\hline G114 & 174.0 & 46.6 & & & & & & \\
\hline M116 & & 55.0 & 36.8 & 32.8 & & & & \\
\hline P118 & & & & 28.0 & & 50.2 & & \\
\hline T120 & & & 72.5 & & 23.6 & & & \\
\hline Y122 & 176.6 & & 37.5 & & & & & \\
\hline H124 & 177.3 & & 27.8 & & & & & \\
\hline A127 & 178.1 & & 18.3 & & & & & \\
\hline G137 & 177.3 & & & & & & \\
\hline
\end{tabular}




\begin{tabular}{|c|c|c|c|c|c|c|c|}
\hline I138 & & 66.4 & 38.3 & 27.0 & 17.1 & 13.4 & \\
\hline A139 & & 55.9 & 18.2 & & & & \\
\hline L140 & 178.6 & & 41.3 & & & & \\
\hline L144 & 178.2 & & 41.4 & & & & \\
\hline V145 & & 67.2 & 31.6 & 22.2 & & & \\
\hline A147/A139 & 179.3 & & 18.5 & & & & \\
\hline A150 & & 179.3 & 18.5 & & & & \\
\hline K155 & 179.7 & 57.9 & 31.9 & & & & \\
\hline I156 & 177.8 & & 37.7 & 29.4 & 17.8 & 14.3 & \\
\hline M157 & & 56.3 & & 30.4 & & & 42.7 \\
\hline F158 & 176.8 & & 41.3 & & & & \\
\hline T172 & & & 71.4 & & 22.3 & & \\
\hline V175 & & 61.1 & 34.4 & & & & \\
\hline R181 & & & 30.1 & & & 43.1 & \\
\hline V184 & 178.1 & & 31.5 & & & & \\
\hline |185 & & & & 29.0 & & 15.1 & \\
\hline A186 & & 53.0 & 19.5 & & & & \\
\hline E187 & & 54.4 & 31.7 & 35.1 & & & \\
\hline K191 & & & 32.5 & 25.3 & & & 42.7 \\
\hline R193 & 174.6 & & 33.7 & & & & \\
\hline R196 & & & 31.2 & & 41.9 & & \\
\hline E198 & & 58.6 & 30.8 & 35.5 & & & \\
\hline H199 & & 56.5 & 31.4 & & & & \\
\hline E202 & & 57.2 & 29.5 & 37.3 & & 183.6 & \\
\hline G203 & 175.5 & 47.6 & & & & & \\
\hline M207 & 175.8 & & 33.7 & & & & \\
\hline K208 & & & 32.6 & 24.9 & & & \\
\hline I209 & 177.5 & & & 27.1 & & 13.5 & \\
\hline $\mathrm{H} 210$ & 178.1 & & 32.5 & & & & \\
\hline D211 & 176.2 & & 39.9 & & & & \\
\hline K213 & 177.6 & & 31.7 & & & & \\
\hline L214 & 179.5 & & 40.9 & & & & \\
\hline V215 & & & 31.6 & 21.9 & & & \\
\hline R216 & & 59.6 & 29.3 & & & & \\
\hline E218 & 177.2 & 59.1 & 29.6 & 36.0 & & 183.0 & \\
\hline $\mathrm{H} 219$ & & 55.9 & 29.9 & & & 183.0 & \\
\hline I221 & & & & 29.3 & & 14.0 & \\
\hline I232 & & 65.3 & 38.4 & 27.2 & & 14.4 & \\
\hline E234 & 176.4 & & 29.7 & 34.7 & & 182.2 & \\
\hline
\end{tabular}




\begin{tabular}{|l|l|l|l|l|l|l|l|l|}
\hline L238 & 178.2 & & 42.2 & & & & & \\
\hline G240 & 175.8 & 47.9 & & & & & & \\
\hline E241 & 176.7 & & 32.4 & & & & & \\
\hline E244 & 176.3 & 58.9 & 28.9 & 36.2 & & 183.9 & & \\
\hline L246 & 179.3 & & 41.9 & & & & & \\
\hline E248 & 176.7 & & 27.7 & 38.8 & & 183.6 & & \\
\hline A251 & & 54.6 & 18.5 & & & & & \\
\hline L253 & & & & 26.9 & & 21.5 & & \\
\hline L254 & 174.8 & & & 27.2 & & & & \\
\hline E258 & & & 30.8 & 37.6 & & 183.5 & & \\
\hline G259 & 172.6 & 44.2 & & & & & & \\
\hline T263 & 177.2 & & 67.0 & & & & & \\
\hline Q266 & 175.3 & & & 32.9 & & & & \\
\hline Q269 & 175.3 & & 33.4 & & & & & \\
\hline A270 & 175.9 & & 21.9 & & & & & \\
\hline R271 & & & 31.4 & & & 44.1 & & \\
\hline H272 & 174.5 & & 32.5 & & & & & \\
\hline E275 & 174.4 & & 34.3 & & & & & \\
\hline I279 & 177.6 & & & 27.2 & & & & \\
\hline Y285 & 175.9 & & 39.6 & & & & & \\
\hline V292 & 174.6 & & 33.3 & & & & & \\
\hline M295 & 177.7 & & 33.7 & & & & & \\
\hline
\end{tabular}


Table S3: List of chemical shift assignments from 3D spectra of SM KirBac1.1 in 3:2 POPC:POPG (w/w) bilayers.

\begin{tabular}{|c|c|c|c|c|c|c|c|c|c|}
\hline Residue & ${ }^{13} \mathrm{C}^{\prime}$ & ${ }^{15} \mathrm{~N}$ & ${ }^{13} \mathrm{C} \alpha$ & ${ }^{13} \mathrm{C} \beta$ & ${ }^{13} \mathrm{C} \gamma 1$ & ${ }^{13} \mathrm{C} \gamma 2$ & ${ }^{13} \mathrm{C} \delta 1$ & ${ }^{13} \mathrm{C} \delta 2$ & ${ }^{13} \mathrm{C} \varepsilon$ \\
\hline $1 \mathrm{M}$ & 178.1 & & 57.7 & 32 & 30.6 & & & & 17.9 \\
\hline $2^{\prime} G$ & 175.7 & 107.1 & 44.8 & & & & & & \\
\hline $2 \mathrm{~N}$ & 178.3 & 117.2 & 55.6 & 37.6 & 175.5 & & & & \\
\hline $3 \mathrm{~V}$ & 177.1 & 115.6 & 65.8 & 32.6 & 22.3 & 21.3 & & & \\
\hline $4 \mathrm{D}$ & 174.3 & 116.5 & 55.1 & 37.3 & & & & & \\
\hline $5 \mathrm{P}$ & 176.9 & 130 & 66.8 & 30.4 & 28 & & 52.6 & & \\
\hline $6 \mathrm{~F}$ & 178.8 & 119.1 & 59 & 37 & 138.6 & & & & \\
\hline $7 S$ & 175.8 & 123 & 62.2 & 62.9 & & & & & \\
\hline $8 \mathrm{P}$ & 176 & 130.3 & 62.6 & 31.8 & 27.6 & & 51.8 & & \\
\hline $9 \mathrm{H}$ & 176 & 122.9 & 55.6 & 31.9 & 135.1 & & & & \\
\hline $10 \mathrm{~S}$ & 175.6 & 123.4 & 54.1 & 63 & & & & & \\
\hline $11 \mathrm{~S}$ & 175.8 & 125.2 & 54.3 & 64.7 & & & & & \\
\hline $12 \mathrm{D}$ & 174.2 & 121.5 & 54.2 & 41.3 & 179.5 & & & & \\
\hline $13 \mathrm{~S}$ & 175.9 & 124.7 & 60.3 & 61 & & & & & \\
\hline $14 \mathrm{~F}$ & 174.6 & 119.9 & 60.1 & 41 & 139 & & & & \\
\hline $15 \mathrm{~A}$ & 173.6 & 122.5 & 54.7 & 17.4 & & & & & \\
\hline $16 \mathrm{Q}$ & 174 & 117.9 & 59.3 & 28 & 35.5 & & 176.8 & & \\
\hline $17 \mathrm{~A}$ & 179.5 & 127 & 51.8 & 19 & & & & & \\
\hline $18 \mathrm{~A}$ & 180.4 & 120.3 & 55.5 & 22.2 & & & & & \\
\hline $19 \mathrm{~S}$ & 178.5 & 115.6 & 63 & 63.5 & & & & & \\
\hline $20 P$ & 178.5 & 130.5 & 64.4 & 31.5 & 27 & & 51.4 & & \\
\hline $21 \mathrm{~A}$ & 174.5 & 122.4 & 55.3 & 18.5 & & & & & \\
\hline $22 R$ & 175.4 & 117.4 & 55.4 & 31.8 & 25.8 & & 43.9 & & \\
\hline $23 \mathrm{~K}$ & & 117.5 & 56 & 31.7 & 27.4 & & & & \\
\hline $24 \mathrm{P}$ & & 138.1 & 62 & & & & & & \\
\hline $25 \mathrm{P}$ & 175 & 130.4 & 61.7 & 30 & 28.2 & & 49.9 & & \\
\hline $26 R$ & 177.6 & 126.6 & 54.6 & 31.6 & 27.3 & & 42.9 & & \\
\hline $27 G$ & 176.4 & 107.4 & 47.5 & & & & & & \\
\hline $28 \mathrm{G}$ & 175.9 & 107.8 & 47.6 & & & & & & \\
\hline $29 R$ & 176.2 & 124.3 & 58.8 & 32.7 & 27.2 & & 42.3 & & \\
\hline $30 \mathrm{R}$ & 176.1 & 117.6 & 58.4 & 32.2 & 27.5 & & 41.3 & & \\
\hline 311 & 178.8 & 125.7 & 58.9 & 40.3 & 27.5 & 17.4 & 14.1 & & \\
\hline $32 \mathrm{~W}$ & 178.8 & 120.7 & 57 & 31.8 & 112.8 & & & & \\
\hline $33 \mathrm{~S}$ & 175.6 & 116.9 & 58 & 65 & & & & & \\
\hline $34 \mathrm{G}$ & 171.5 & 111.4 & 44.5 & & & & & & \\
\hline $35 \mathrm{~T}$ & 177.3 & 121.2 & 57.5 & 65.6 & 22.3 & & & & \\
\hline $36 \mathrm{R}$ & 175.9 & 120.5 & 58.5 & 29.8 & 26.5 & & 41.4 & & \\
\hline $37 \mathrm{E}$ & 176.5 & 120 & 58.5 & 29.7 & 33.4 & & 182.3 & & \\
\hline
\end{tabular}




\begin{tabular}{|c|c|c|c|c|c|c|c|c|c|}
\hline $38 \mathrm{~V}$ & 177.9 & 120 & 66.4 & 31.1 & 23.8 & 22.2 & & & \\
\hline 391 & 177.5 & 119 & 67.1 & 37.7 & & 17.8 & 13.6 & & \\
\hline $40 \mathrm{~A}$ & 179 & 122.2 & 54.9 & 17.8 & & & & & \\
\hline $41 \mathrm{Y}$ & 176.2 & 122.2 & 58.3 & 36.7 & 131 & & & & \\
\hline $42 G$ & 174.4 & 106.6 & 47.4 & & & & & & \\
\hline $43 \mathrm{M}$ & & 122.2 & 55 & 34.8 & 29.9 & & & & 17.36 \\
\hline $44 \mathrm{P}$ & 176.8 & 137.2 & 63.4 & 31.2 & 27 & & 52.1 & & \\
\hline $45 \mathrm{~A}$ & 179.4 & 123.1 & 55.9 & 18.1 & & & & & \\
\hline $46 S$ & 177.9 & 119.1 & 62 & 62.3 & & & & & \\
\hline $47 \mathrm{~V}$ & 177.4 & 122.8 & 67.3 & 31.4 & 23.5 & 21.3 & & & \\
\hline $48 \mathrm{~W}$ & 180.2 & 121.4 & 61.7 & 27.9 & 111.6 & & & & \\
\hline $49 R$ & 177.7 & 117.8 & 58.8 & 29 & 28.2 & & 43.1 & & \\
\hline $50 \mathrm{D}$ & 175.2 & 118.9 & 56.3 & 37.6 & 178.1 & & & & \\
\hline $51 \mathrm{~L}$ & 178 & 117.9 & 58 & 39.4 & 26.5 & & 24.1 & 23.3 & \\
\hline $52 Y$ & 175.7 & 120.3 & 61.7 & 37.8 & & & & & \\
\hline $53 Y$ & 179 & 120.8 & 61.7 & 38 & 128.3 & & & & \\
\hline $54 \mathrm{~W}$ & 173.8 & 119.9 & 61.3 & 27.9 & 107.7 & & & & \\
\hline $55 \mathrm{~A}$ & 179 & 127.3 & 55.6 & 18.3 & & & & & \\
\hline $56 \mathrm{~L}$ & 180.2 & 118.1 & 58 & 39.3 & 26.9 & & 24.2 & 22.9 & \\
\hline $57 \mathrm{~K}$ & 176.7 & 120.8 & 58.4 & 31.1 & 27.4 & & & & \\
\hline $58 \mathrm{~V}$ & 177.3 & 121.9 & 65.7 & 31.2 & 23 & 21.6 & & & \\
\hline $59 S$ & 175.7 & 115.2 & 63 & 63.6 & & & & & \\
\hline $60 \mathrm{~W}$ & & 120.4 & 59.9 & 28.3 & 112.2 & & & & \\
\hline 61P & 177.1 & 130.8 & 65.7 & 31.6 & 28 & & 50.4 & & \\
\hline $62 \mathrm{~V}$ & 177.3 & 120.4 & 68.2 & 31.1 & 22.5 & 21.5 & & & \\
\hline $63 \mathrm{~F}$ & 176 & 120 & 62.7 & 38.6 & & & & & \\
\hline $64 \mathrm{~F}$ & 175.9 & 116.7 & 62.5 & 38.8 & & & & & \\
\hline $65 \mathrm{~A}$ & 178.9 & 117.2 & 55.6 & 17.35 & & & & & \\
\hline $66 S$ & 176.1 & 115.7 & 62.7 & 63.1 & & & & & \\
\hline $67 \mathrm{~L}$ & 175.4 & 122.4 & 58 & 41.5 & 25.8 & & 23.3 & 22.2 & \\
\hline $68 \mathrm{~A}$ & 178.1 & 123.1 & 55.7 & 18 & & & & & \\
\hline $69 \mathrm{~A}$ & 180 & 123.2 & 55.8 & 18.6 & & & & & \\
\hline $70 \mathrm{~L}$ & 174.9 & 120.8 & 57.8 & 41 & 26.3 & & 23.5 & 22.5 & \\
\hline $71 \mathrm{~F}$ & 176.2 & 119.7 & 62.5 & 38.6 & & & & & \\
\hline $72 \mathrm{~V}$ & 178 & 118.9 & 67.4 & 31.4 & 23.5 & 21.8 & & & \\
\hline $73 \mathrm{~V}$ & 175.9 & 118.8 & 67.7 & 31.4 & 23.5 & 22 & & & \\
\hline $74 \mathrm{~N}$ & 177.9 & 120.3 & 58.3 & 39.4 & 176.4 & & & & \\
\hline $75 \mathrm{~N}$ & 179.3 & 121.1 & 55.7 & 36.7 & 177.7 & & & & \\
\hline $76 \mathrm{~T}$ & 175.9 & 118.8 & 67.1 & 68.3 & & 21 & & & \\
\hline $77 \mathrm{~L}$ & 178.6 & 119.5 & 58 & 41.4 & 26.4 & & 23.1 & 21.5 & \\
\hline $78 \mathrm{~F}$ & 178.7 & 115.7 & 60 & 38.1 & & & & & \\
\hline
\end{tabular}




\begin{tabular}{|c|c|c|c|c|c|c|c|c|c|}
\hline $79 A$ & 180.8 & 122.8 & 55.6 & 18.1 & & & & & \\
\hline $80 \mathrm{~L}$ & 176.2 & 119.1 & 57.7 & 41.5 & 26.2 & & 24.1 & 23 & \\
\hline $81 \mathrm{~L}$ & 177.9 & 118.7 & 57.7 & 39.5 & 25.7 & & 24.2 & 22.9 & \\
\hline $82 \mathrm{Y}$ & 177.9 & 119.6 & 61 & 37.8 & 129.3 & & & & \\
\hline $83 \mathrm{Q}$ & 176.1 & 120 & 57.1 & 31.5 & 32.8 & & 179.5 & & \\
\hline $84 \mathrm{~L}$ & 179.1 & 122.2 & 57.2 & 41.6 & 26.2 & & & & \\
\hline $85 G$ & 174.3 & 107.4 & 46.2 & & & & & & \\
\hline $86 \mathrm{D}$ & 175 & 123.1 & 54.4 & 40 & 180.7 & & & & \\
\hline $87 \mathrm{~A}$ & 172 & 120.9 & 54.3 & 17.9 & & & & & \\
\hline $88 \mathrm{P}$ & 176.6 & 134.4 & 62.2 & 31.1 & 25.9 & & 50.6 & & \\
\hline 891 & 175.5 & 117.4 & 58.33 & 41 & 27.7 & 17.1 & 13.1 & & \\
\hline $90 \mathrm{~A}$ & 175.9 & 130.7 & 52.18 & 18.4 & & & & & \\
\hline $91 \mathrm{~N}$ & 174.6 & 113.5 & 53.4 & 36.8 & 178.5 & & & & \\
\hline $92 \mathrm{Q}$ & 176.7 & 117.9 & 58.8 & 26.7 & 33.8 & & 179.8 & & \\
\hline $93 \mathrm{~S}$ & 175.6 & 118.5 & 58.4 & 66.5 & & & & & \\
\hline $94 \mathrm{P}$ & 175.3 & 131.4 & 64.6 & & & & & & \\
\hline $95 \mathrm{P}$ & 179.1 & 131.1 & 60 & 33.1 & 26.7 & & & & \\
\hline $96 \mathrm{G}$ & 175.9 & 102.2 & 46.5 & & & & & & \\
\hline $97 \mathrm{~F}$ & 178.7 & 125 & 58.7 & 41.8 & & & & & \\
\hline $98 \mathrm{~V}$ & 177.5 & 118 & 67.2 & 31.8 & 24 & 21.8 & & & \\
\hline $99 G$ & 175.3 & 109 & 48.2 & & & & & & \\
\hline $100 \mathrm{~A}$ & 177.2 & 123 & 55.1 & 18.34 & & & & & \\
\hline $101 \mathrm{~F}$ & 178.2 & 119.9 & 61.5 & 37.7 & & & 131.9 & & \\
\hline $102 \mathrm{~F}$ & 176.7 & 122 & 61.6 & 38.2 & & & 130.6 & & \\
\hline $103 \mathrm{~F}$ & 176.5 & 121.2 & 61.8 & 39.2 & & & 129.1 & & \\
\hline $104 S$ & 177.1 & 119 & 61.6 & 62 & & & & & \\
\hline $105 \mathrm{~V}$ & 177.7 & 117.6 & 65.5 & 30.6 & 22 & 21.5 & & & \\
\hline 106E & 174.1 & 119.1 & 58.5 & 29.2 & 38 & & 182.2 & & \\
\hline $107 \mathrm{~T}$ & 176.4 & 109.8 & 62.4 & 69.3 & 20.7 & & & & \\
\hline 108L & 175.5 & 122.6 & 58.2 & 40.9 & 26.6 & & 24.4 & 22.2 & \\
\hline $109 \mathrm{~A}$ & 176.2 & 130.9 & 52 & 18 & & & & & \\
\hline $110 \mathrm{~T}$ & 172.5 & 109.3 & 63.5 & 69.5 & 21 & & & & \\
\hline $111 \mathrm{~V}$ & 179.3 & 120.8 & 65.4 & 33.3 & 21.1 & 20.5 & & & \\
\hline $112 \mathrm{G}$ & 175.1 & 102.2 & 48.2 & & & & & & \\
\hline $113 Y$ & 179.4 & 118.1 & 60.5 & 37.5 & & & & & \\
\hline $114 G$ & 173.7 & 102.5 & 46.6 & & & & & & \\
\hline 115D & 178.9 & 119.2 & 55.7 & 40 & 176.9 & & & & \\
\hline $116 \mathrm{M}$ & 179 & 120.8 & 55.2 & 36.6 & 32.7 & & & & 18.1 \\
\hline $117 \mathrm{H}$ & 176 & 120.7 & 54.6 & 31.6 & & & & & \\
\hline $118 \mathrm{P}$ & 175.3 & 137.1 & 63.5 & 32.2 & 27.5 & & 50.4 & & \\
\hline $119 Q$ & 173.9 & 116 & 53.6 & 29 & 30.6 & & 180.8 & & \\
\hline
\end{tabular}




\begin{tabular}{|c|c|c|c|c|c|c|c|c|c|}
\hline 120T & 174.5 & 110.5 & 58.7 & 72 & & 23.1 & & & \\
\hline $121 \mathrm{~V}$ & 177.5 & 124.1 & 68.4 & 31.1 & 24.2 & 22 & & & \\
\hline $122 \mathrm{Y}$ & 176.1 & 120 & 62.6 & 38 & 134.6 & & & & \\
\hline $123 \mathrm{~A}$ & 177.2 & 117.4 & 54.9 & 17.9 & & & & & \\
\hline $124 \mathrm{H}$ & 174.9 & 118 & 58.6 & 27.2 & 131.8 & & & & \\
\hline $125 \mathrm{~A}$ & 174.9 & 124.7 & 54.4 & 17.9 & & & & & \\
\hline 1261 & 177.6 & 121.1 & 64 & 37.5 & 28.6 & 17.3 & 13.5 & & \\
\hline $127 \mathrm{~A}$ & 176.1 & 120.6 & 56.6 & 18.4 & & & & & \\
\hline $128 \mathrm{~T}$ & 175.2 & 118.2 & 68.6 & 67.9 & 21.2 & & & & \\
\hline $129 \mathrm{~L}$ & 178.3 & 120.5 & 58.4 & 41.3 & 27.8 & & 23.1 & 22.75 & \\
\hline $130 \mathrm{E}$ & 177 & 118.5 & 60.7 & 28.5 & 36.6 & & 179.9 & & \\
\hline $131 \mathrm{C}$ & 176.9 & 118.7 & 65.7 & 29.6 & & & & & \\
\hline $132 \mathrm{~F}$ & 177.2 & 119.5 & 61.6 & 38.9 & & & & & \\
\hline $133 \mathrm{~V}$ & 177.1 & 122.5 & 67.1 & 31.4 & 23.3 & 23 & & & \\
\hline $134 \mathrm{G}$ & 175.7 & 107.1 & 48.2 & & & & & & \\
\hline $135 \mathrm{M}$ & 178.6 & 122.2 & 58.3 & 32.3 & 35.6 & & & & 17.5 \\
\hline $136 \mathrm{~S}$ & 175.9 & 114.7 & 63.6 & 64 & & & & & \\
\hline $137 G$ & 175.4 & 109.5 & 48.9 & & & & & & \\
\hline 1381 & 177.3 & 121.4 & 66.1 & 38.1 & 29.3 & 17.2 & 14 & & \\
\hline $139 A$ & 179.2 & 121 & 55.6 & 18.3 & & & & & \\
\hline $140 \mathrm{~L}$ & 178.5 & 118.7 & 58.4 & 41 & 27 & & 23.3 & 22.1 & \\
\hline $141 S$ & 175.5 & 114.4 & 63.3 & 63 & & & & & \\
\hline $142 \mathrm{~T}$ & 176.5 & 118.9 & 67.6 & 68.34 & 21.9 & & & & \\
\hline $143 G$ & 175.8 & 106.6 & 47.9 & & & & & & \\
\hline $144 \mathrm{~L}$ & 178.6 & 122 & 58 & 41.4 & 28.5 & & 23.4 & 22.1 & \\
\hline $145 \mathrm{~V}$ & 176 & 119.5 & 67.3 & 31.5 & 23.5 & 22.1 & & & \\
\hline $146 \mathrm{~F}$ & 176 & 123.8 & 62.4 & 38.7 & & & & & \\
\hline $147 \mathrm{~A}$ & 179.7 & 120.5 & 55.5 & 19.2 & & & & & \\
\hline $148 R$ & 178 & 120.5 & 58 & 29.5 & 26.6 & & 42.3 & & \\
\hline $149 \mathrm{~F}$ & 174.8 & 120.3 & 60.6 & 39.4 & & & & & \\
\hline $150 \mathrm{~A}$ & 174.1 & 125.4 & 54.3 & 18 & & & & & \\
\hline $151 R$ & 172 & 125.5 & 54.5 & 33.3 & 26.3 & & 42.9 & & \\
\hline $152 \mathrm{P}$ & 175.2 & 134.4 & 61.9 & 29.8 & 27.5 & & 50.5 & & \\
\hline $153 R$ & 175.1 & 121.8 & 55.5 & 32.8 & 26.8 & & 42.1 & & \\
\hline $154 \mathrm{~A}$ & 177.6 & 120.2 & 55.4 & 22.2 & & & & & \\
\hline $155 \mathrm{~K}$ & 179.2 & 120.7 & 57.9 & 32.2 & 24.1 & & 28.5 & & 41.5 \\
\hline $156 \mid$ & 177.4 & 121.8 & 64.6 & 37.9 & 29.5 & 17.1 & 14.1 & & \\
\hline $157 \mathrm{M}$ & 175.2 & 117.6 & 58.3 & 32.3 & 35.7 & & & & 16.9 \\
\hline $158 \mathrm{~F}$ & 175.9 & 124.3 & 55.4 & 41.3 & 139.6 & & & & \\
\hline $159 \mathrm{~A}$ & 175.3 & 118.3 & 54.7 & 19.2 & & & & & \\
\hline $160 \mathrm{R}$ & 174.7 & 122.7 & 54.3 & 34.6 & 27.6 & & 44 & & \\
\hline
\end{tabular}




\begin{tabular}{|c|c|c|c|c|c|c|c|c|c|}
\hline $161 \mathrm{H}$ & 174.2 & 120.6 & 53.8 & 32.8 & & & & & \\
\hline $162 \mathrm{~A}$ & 174.7 & 122.3 & 53.4 & 21.7 & & & & & \\
\hline 1631 & 177.5 & 117.6 & 57.8 & 42.6 & 28.3 & 18.5 & 14.2 & & \\
\hline $164 \mathrm{~V}$ & 175 & 118.6 & 59.9 & 31.9 & 21.03 & 21.4 & & & \\
\hline $165 \mathrm{R}$ & & 122.6 & 56.1 & 31.2 & 26.9 & & 42.2 & & \\
\hline $166 \mathrm{P}$ & 175.5 & 133.8 & 64.7 & 32.1 & 27.3 & & 51.8 & & \\
\hline $167 \mathrm{~F}$ & 177.8 & 121.6 & 55.1 & 42.6 & 138.2 & & & & \\
\hline $168 \mathrm{~N}$ & 173 & 121 & 55.3 & 36.6 & 177.9 & & & & \\
\hline $169 \mathrm{G}$ & 174.2 & 105.7 & 46.7 & & & & & & \\
\hline 170R & 174.8 & 121.2 & 53.6 & 32.6 & 26.7 & & 46.8 & & \\
\hline $171 \mathrm{M}$ & 179 & 115.8 & 53.7 & 30.7 & 29.2 & & & & 18.8 \\
\hline $172 \mathrm{~T}$ & 174.7 & 109.8 & 58.9 & 71.9 & 21.9 & & & & \\
\hline $173 \mathrm{~L}$ & 175.8 & 116.8 & 54.8 & 44.5 & 25.5 & & 22.6 & 22.1 & \\
\hline $174 \mathrm{M}$ & 178 & 121.1 & 55.5 & 36.6 & 31.6 & & & & 18.1 \\
\hline $175 \mathrm{~V}$ & 176.2 & 122.3 & 61.3 & 34.2 & 22.7 & 21.3 & & & \\
\hline $176 \mathrm{R}$ & 176 & 121 & 55.1 & 32.7 & 27.1 & & 41.8 & & \\
\hline $177 \mathrm{~A}$ & 174.6 & 124.8 & 52.6 & 20.2 & & & & & \\
\hline $178 \mathrm{~A}$ & 178.5 & 120.4 & 52.2 & 20.9 & & & & & \\
\hline $179 \mathrm{~N}$ & 176.4 & 113.2 & 53.2 & 37.1 & 178.5 & & & & \\
\hline $180 \mathrm{~A}$ & 174.8 & 121.2 & 53.8 & 18.5 & & & & & \\
\hline 181R & 174.2 & 117.8 & 56.4 & 29 & 27.42 & & 43.1 & & \\
\hline $182 Q$ & 176.2 & 121.8 & 54.4 & 29.8 & 31.5 & & 180.6 & & \\
\hline $183 \mathrm{~N}$ & 177.4 & 120.4 & 55.3 & 38.2 & 180 & & & & \\
\hline $184 \mathrm{~V}$ & 177.6 & 117 & 67.1 & 31.2 & 23.5 & 21.8 & & & \\
\hline 1851 & 177.4 & 119.4 & 59.8 & 42.6 & 28.5 & 18.8 & 15.3 & & \\
\hline $186 \mathrm{~A}$ & 176.1 & 118.5 & 53.1 & 19.1 & & & & & \\
\hline $187 \mathrm{E}$ & 174.1 & 125.8 & 54.1 & 31.6 & 35.5 & & 182.1 & & \\
\hline $188 \mathrm{~A}$ & 176.1 & 126.8 & 50.7 & 21.7 & & & & & \\
\hline $189 \mathrm{R}$ & 177 & 118 & 55.2 & 32.6 & 26.3 & & 43.9 & & \\
\hline $190 \mathrm{~A}$ & 176.8 & 113.3 & 52.1 & 20.6 & & & & & \\
\hline $191 \mathrm{~K}$ & 174.7 & 116.8 & 54.4 & 32.4 & 25.2 & & 29 & & 42.8 \\
\hline $192 \mathrm{M}$ & 174.5 & 124 & 54 & 34.3 & 33 & & & & 17.9 \\
\hline $193 R$ & 174.6 & 123.3 & 53.1 & 33.7 & 26.6 & & 45.8 & & \\
\hline 194L & 174.8 & 124.1 & 54.6 & 40.6 & 27.5 & & 23.3 & 23.6 & \\
\hline $195 \mathrm{M}$ & 175.6 & 115.4 & 55 & 35.9 & 33 & & & & 17 \\
\hline 196R & 176 & 113.4 & 56.6 & 31.7 & 26.7 & & 40.6 & & \\
\hline 197R & 175.1 & 119.4 & 56.3 & 31.7 & 26.9 & & 43 & & \\
\hline $198 \mathrm{E}$ & 176.6 & 118.5 & 58.8 & 30.6 & 35.4 & & 182.4 & & \\
\hline $199 \mathrm{H}$ & 177.3 & 120.1 & 56.6 & 31.5 & 131.9 & & & & \\
\hline $200 S$ & 176.7 & 116.5 & 58.1 & 64.2 & & & & & \\
\hline $201 \mathrm{~S}$ & 178.4 & 115.4 & 55.5 & 65.1 & & & & & \\
\hline
\end{tabular}




\begin{tabular}{|c|c|c|c|c|c|c|c|c|c|}
\hline $202 \mathrm{E}$ & 178.7 & 119.8 & 57.7 & 29.2 & 37.7 & & 182.8 & & \\
\hline $203 G$ & 174.4 & 104.5 & 48.7 & & & & & & \\
\hline $204 Y$ & 176.7 & 121.4 & 58.8 & 38.2 & 133.2 & & & & \\
\hline $205 S$ & 175.7 & 119.2 & 56.3 & 64.7 & & & & & \\
\hline $206 \mathrm{~L}$ & 175.7 & 121.9 & 54.6 & 42.3 & 28.3 & & 25.6 & 26.8 & \\
\hline $207 \mathrm{M}$ & 175.7 & 121.2 & 54.4 & 33.7 & 31.9 & & & & 18 \\
\hline $208 \mathrm{~K}$ & 178.8 & 117.1 & 54.9 & 32.4 & 25.6 & & 28.8 & & 40.4 \\
\hline 2091 & 176.8 & 120.4 & 58.9 & 41.5 & 29.1 & 19.2 & 13.3 & & \\
\hline $210 \mathrm{H}$ & 178.1 & 121.3 & 55 & 32.8 & 130.7 & & & & \\
\hline 211D & 176.1 & 122.8 & 54 & 39.4 & 178.9 & & & & \\
\hline $212 \mathrm{~L}$ & 177.8 & 117.8 & 55.6 & 41.8 & 25.9 & & 22.6 & 23.3 & \\
\hline $213 K$ & 177.3 & 117.5 & 57.8 & 31.7 & 25.5 & & 28.4 & & 41.6 \\
\hline $214 \mathrm{~L}$ & 179.5 & 116 & 57.6 & 41.3 & 26.3 & & 23.5 & 23.4 & \\
\hline $215 \mathrm{~V}$ & 177.4 & 120.4 & 65.6 & 31.2 & 21.5 & 22.9 & & & \\
\hline $216 \mathrm{R}$ & 179.2 & 119.4 & 59.3 & 29.6 & 28.1 & & 42.25 & & \\
\hline $217 \mathrm{~N}$ & 178.5 & 117.8 & 53.4 & 42 & 176.1 & & & & \\
\hline $218 \mathrm{E}$ & 177.1 & 117.3 & 58.8 & 29.4 & 35.6 & & 181 & & \\
\hline $219 \mathrm{H}$ & & 120.4 & 55.9 & 30.8 & 130.6 & & & & \\
\hline $220 \mathrm{P}$ & 179.2 & 133.7 & 65.2 & 32.3 & 26.8 & & 50.6 & & \\
\hline 2211 & 178.1 & 118.9 & 66 & 38.4 & 29.4 & 17.3 & 14.1 & & \\
\hline $222 \mathrm{~F}$ & 176.5 & 115.4 & 57.8 & 41 & 138.3 & & 132.1 & & \\
\hline $223 \mathrm{~L}$ & 174.8 & 122.3 & 56.2 & 42.4 & 27.2 & & 25.5 & 25.9 & \\
\hline $224 \mathrm{~L}$ & 178.3 & 117.7 & 56.4 & 42.1 & 26.1 & & 23.7 & 23.3 & \\
\hline $225 G$ & 174.7 & 104.8 & 44.9 & & & & & & \\
\hline $226 \mathrm{~W}$ & 178.3 & 117.1 & 55.4 & 29.5 & 108.2 & & & & \\
\hline $227 \mathrm{~N}$ & 176.2 & 125 & 52.8 & 39.9 & 174.7 & & & & \\
\hline $228 \mathrm{M}$ & 176.2 & 116.2 & 55.6 & 32.3 & 31.3 & & & & 17.8 \\
\hline $229 \mathrm{M}$ & 176.4 & 119.3 & 55.8 & 34 & 31.6 & & & & 18.3 \\
\hline $230 \mathrm{H}$ & 177.6 & 117.3 & 55.3 & 30.5 & 133.9 & & & 125.5 & \\
\hline $231 \mathrm{~V}$ & 178 & 122.7 & 59.6 & 34.3 & 21.7 & 20.9 & & & \\
\hline 2321 & 177.6 & 119.4 & 65.2 & 38.7 & 26.9 & 17.6 & 14.2 & & \\
\hline 233D & 177.8 & 121.4 & 57.6 & 39.2 & 178.9 & & & & \\
\hline $234 \mathrm{E}$ & 177 & 115.7 & 57.6 & 30.2 & 34.7 & & 182.8 & & \\
\hline $235 \mathrm{~S}$ & 175.2 & 119.6 & 55.6 & 68.3 & & & & & \\
\hline $236 \mathrm{~S}$ & 174.3 & 124.2 & 55.2 & 63.1 & & & & & \\
\hline $237 \mathrm{P}$ & 178.2 & 129.9 & 66.5 & 29.6 & 26.8 & & 50.2 & & \\
\hline $238 \mathrm{~L}$ & 178.4 & 116.2 & 55.6 & 41.6 & 27 & & 23.7 & 23.5 & \\
\hline $239 \mathrm{~F}$ & 178 & 116.3 & 63.1 & 38.3 & & & 130.5 & & \\
\hline $240 \mathrm{G}$ & 175 & 109.7 & 47.9 & & & & & & \\
\hline $241 \mathrm{E}$ & 176.8 & 121.9 & 57.8 & 32.4 & 35.9 & & 180.8 & & \\
\hline $242 \mathrm{~T}$ & 173.6 & 112.7 & 59.6 & 72.4 & & 21.5 & & & \\
\hline
\end{tabular}




\begin{tabular}{|c|c|c|c|c|c|c|c|c|c|}
\hline $243 \mathrm{P}$ & 177.8 & 131 & 66.4 & 31.1 & 28.9 & & 50.8 & & \\
\hline $244 \mathrm{E}$ & 176.5 & 122.7 & 59.1 & 28.8 & 36 & & 180.7 & & \\
\hline $245 S$ & 176.1 & 118.1 & 62.7 & 63 & & & & & \\
\hline $246 \mathrm{~L}$ & 178.6 & 123.7 & 58.2 & 41.7 & 26.9 & & 23.5 & 23.1 & \\
\hline $247 A$ & 179.5 & 122.1 & 55.4 & 18.1 & & & & & \\
\hline $248 \mathrm{E}$ & 175.6 & 119 & 58.4 & 28.1 & 38 & & 181.9 & & \\
\hline $249 G$ & 171.4 & 109.9 & 45.9 & & & & & & \\
\hline $250 \mathrm{R}$ & 176.7 & 123.5 & 54.4 & 27.6 & 25.6 & & 41.9 & & \\
\hline $251 \mathrm{~A}$ & 175 & 121.3 & 54.6 & 18.2 & & & & & \\
\hline 252M & 175.6 & 120.4 & 54 & 34.6 & 32.8 & & & & 17.5 \\
\hline $253 \mathrm{~L}$ & 178.8 & 120.5 & 54.5 & 43.3 & 27.4 & & 22.8 & 21.6 & \\
\hline $254 \mathrm{~L}$ & 174.6 & 119.7 & 54.5 & 45.6 & 27.2 & & 23.1 & 21.7 & \\
\hline $255 \mathrm{~V}$ & 178.2 & 118 & 60.3 & 34.3 & 22.2 & 21.2 & & & \\
\hline $256 \mathrm{M}$ & 174.7 & 117.6 & 55 & 35.8 & 34.7 & & & & 18.2 \\
\hline 2571 & 178.4 & 117.6 & 59 & 42 & 27.4 & 20.7 & 13.6 & & \\
\hline $258 \mathrm{E}$ & 178.6 & 118 & 56.4 & 30.6 & 37.3 & & 182.2 & & \\
\hline $259 \mathrm{G}$ & 172.5 & 105 & 44.2 & & & & & & \\
\hline $260 S$ & 175.1 & 121.1 & 55.1 & 65.1 & & & & & \\
\hline 261D & 177.7 & 120.1 & 55.7 & 42.7 & 179.3 & & & & \\
\hline $262 \mathrm{E}$ & 175.7 & 117.9 & 58.1 & 31.7 & 35.7 & & 182.6 & & \\
\hline $263 \mathrm{~T}$ & 175.9 & 118.6 & 60.1 & 67.7 & & 21.2 & & & \\
\hline $264 \mathrm{~T}$ & 173.3 & 123.6 & 60.5 & 69.6 & & 21.4 & & & \\
\hline $265 \mathrm{~A}$ & 175.4 & 129.7 & 50.4 & 20.3 & & & & & \\
\hline $266 \mathrm{Q}$ & 174.5 & 122.1 & 54.7 & 31.3 & 32.6 & & 180.4 & & \\
\hline $267 \mathrm{~V}$ & 176.4 & 123.4 & 61.1 & 34.9 & 20.4 & 20.1 & & & \\
\hline $268 \mathrm{M}$ & 176.6 & 126 & 54.2 & 35.4 & 33.4 & & & & 17.6 \\
\hline $269 \mathrm{Q}$ & 174.9 & 117.2 & 55.2 & 33.2 & 34.7 & & 177.7 & & \\
\hline $270 \mathrm{~A}$ & 175 & 125 & 52.2 & 21.7 & & & & & \\
\hline $271 R$ & 174.8 & 126.2 & 54.4 & 31.6 & 26.8 & & 44.2 & & \\
\hline $272 \mathrm{H}$ & 176.1 & 121.4 & 54.1 & 33.1 & 131.3 & & & & \\
\hline $273 \mathrm{~A}$ & 175.4 & 127.7 & 52.7 & 19.1 & & & & & \\
\hline $274 W$ & 178.2 & 123.7 & 58.7 & 32.8 & 113.5 & & & & \\
\hline $275 \mathrm{E}$ & 174.5 & 115.8 & 55.4 & 31.3 & 34.1 & & 182.9 & & \\
\hline $276 \mathrm{H}$ & 175.7 & 122.3 & 59.9 & 27.2 & 133.8 & & & & \\
\hline $277 \mathrm{D}$ & 178.6 & 122.5 & 55.9 & 39.4 & 176 & & & & \\
\hline $278 D$ & 176.6 & 117.9 & 55.6 & 37.8 & 178.6 & & & & \\
\hline 2791 & 176.9 & 120.2 & 57.9 & 41.2 & 27.5 & 17.1 & 14.3 & & \\
\hline $280 \mathrm{R}$ & 174.6 & 122.3 & 55.1 & 34.8 & 26.9 & & 42.1 & & \\
\hline $281 W$ & 178.2 & 124.6 & 55.7 & 33.3 & 113.4 & & & & \\
\hline $282 \mathrm{H}$ & 178.9 & 115.7 & 59.5 & 25.7 & & & & 122.6 & \\
\hline $283 \mathrm{H}$ & 179.8 & 119.8 & 58.2 & 27 & 135.7 & & & & \\
\hline
\end{tabular}




\begin{tabular}{|l|l|l|l|l|l|l|l|l|l|}
\hline $284 \mathrm{R}$ & 179.1 & 124.1 & 55.2 & 32.3 & 27.7 & & 41 & & \\
\hline $285 \mathrm{Y}$ & 176 & 121.3 & 61.7 & 39.6 & 132.2 & & & & \\
\hline $286 \mathrm{~V}$ & 178.6 & 124.4 & 61.7 & 32.5 & 22.5 & 21.3 & & & \\
\hline $287 \mathrm{D}$ & 174.6 & 121.1 & 55.6 & 44.2 & 176.7 & & & & \\
\hline $288 \mathrm{~L}$ & 176.9 & 116.2 & 57.8 & 41 & 26.5 & & 23.5 & 22.7 & \\
\hline $289 \mathrm{M}$ & 178.4 & 119.2 & 55.6 & 34 & 31.6 & & & & 17.7 \\
\hline 290S & 176.9 & 121.3 & 56.8 & 63.5 & & & & & \\
\hline 291D & 174.7 & 124.2 & 54.8 & 40.7 & 176.1 & & & & \\
\hline 292V & 174.6 & 122.7 & 60.8 & 33.3 & 21.3 & 21.6 & & & \\
\hline $293 \mathrm{D}$ & 177.8 & 125.86 & 54.7 & 43.1 & 174.8 & & & & \\
\hline $294 \mathrm{G}$ & 173.5 & 106.9 & 45.5 & & & & & & \\
\hline $295 \mathrm{M}$ & 177 & 121.2 & 54.5 & 33.7 & 31.7 & & & & 18 \\
\hline $296 \mathrm{~T}$ & 176.1 & 119 & 60.9 & 70.2 & & 21.5 & & & \\
\hline $297 \mathrm{H}$ & 174.5 & 126 & 55.2 & 34.7 & 130.3 & & & & \\
\hline $298 \mathrm{I}$ & 174.5 & 126.3 & 60.4 & 39.8 & 27.2 & 18.5 & 14.5 & & \\
\hline $299 \mathrm{D}$ & 177.2 & 125.8 & 54.4 & 41.6 & 175.9 & & & & \\
\hline $300 \mathrm{Y}$ & 176 & 118.2 & 55 & 39.3 & 131.1 & & 136.7 & & \\
\hline $301 \mathrm{~T}$ & 176 & 119.9 & 61.7 & 68.4 & & 22.2 & & & \\
\hline
\end{tabular}


Table S4: List of chemical shifts from 3D spectra of SM KirBac1.1 in POPC bilayers.

\begin{tabular}{|c|c|c|c|c|c|c|c|c|c|}
\hline Residue & ${ }^{13} \mathrm{C}^{\prime}$ & ${ }^{15} \mathrm{~N}$ & ${ }^{13} \mathrm{C} \alpha$ & ${ }^{13} \mathrm{C} \beta$ & ${ }^{13} \mathrm{C} \gamma 1$ & ${ }^{13} \mathrm{C} \gamma 2$ & ${ }^{13} \mathrm{C} \delta 1$ & ${ }^{13} \mathrm{C} \delta 2$ & ${ }^{13} \mathrm{C} \varepsilon$ \\
\hline $1 \mathrm{M}$ & 177.8 & & 57.7 & 32.1 & 31.1 & & & & 19.1 \\
\hline $2^{\prime} G$ & 177.2 & 107.1 & 46.5 & & & & & & \\
\hline $2 \mathrm{~N}$ & 177.5 & 114.6 & 55.4 & 37.5 & 179.5 & & & & \\
\hline $3 \mathrm{~V}$ & 177.4 & 116.1 & 65.7 & 31.3 & 23.9 & & & & \\
\hline 4D & & 120.4 & 55.4 & 37.7 & & & & & \\
\hline $5 \mathrm{P}$ & 175.8 & 135.6 & 62.1 & 30.5 & 27.1 & & 51.3 & & \\
\hline $6 \mathrm{~F}$ & 176.5 & 119.5 & 59 & 37 & 138.8 & & & & \\
\hline $7 S$ & 178.6 & 120.5 & 62.2 & 62.9 & & & & & \\
\hline $8 \mathrm{P}$ & 176 & 130.9 & 63.5 & 31.4 & 27.3 & & 51.3 & & \\
\hline $9 \mathrm{H}$ & 177.3 & 120 & 55.7 & 31.6 & 132.7 & & & & \\
\hline $10 \mathrm{~S}$ & 177.3 & 118.2 & 54.1 & 62.7 & & & & & \\
\hline $11 \mathrm{~S}$ & 174.7 & 125.1 & 55 & 64.6 & & & & & \\
\hline $12 \mathrm{D}$ & 175.4 & 121.5 & 54.2 & 41.9 & 178.4 & & & & \\
\hline $13 S$ & 175.5 & 123.6 & 61.6 & 61.1 & & & & & \\
\hline $14 \mathrm{~F}$ & 175.6 & 123.7 & 59.9 & 37.6 & 140.3 & & & & \\
\hline $15 \mathrm{~A}$ & 179 & 124 & 55 & 17.7 & & & & & \\
\hline $16 Q$ & 174.7 & 120 & 59 & 29.2 & 30.1 & & 180.4 & & \\
\hline $17 \mathrm{~A}$ & 176.6 & 128 & 51.4 & 22.5 & & & & & \\
\hline $18 \mathrm{~A}$ & 180.4 & 120.4 & 55.7 & 22 & & & & & \\
\hline $19 S$ & & 115.5 & 63.4 & 62.3 & & & & & \\
\hline $20 P$ & 175.8 & 130.8 & 63.7 & 31.4 & 27.2 & & 51.3 & & \\
\hline $21 \mathrm{~A}$ & 179 & 123.1 & 55.7 & 18.2 & & & & & \\
\hline $22 \mathrm{R}$ & 175.4 & 117.4 & 55.4 & 31.8 & 25.8 & & 43.9 & & \\
\hline $23 \mathrm{~K}$ & & 117.5 & 57.4 & 32.4 & 28 & & & & \\
\hline $24 \mathrm{P}$ & 173.2 & 138.1 & 61.8 & & & & 50.9 & & \\
\hline $25 \mathrm{P}$ & 173.8 & 133.9 & 61.9 & 30.4 & 28.1 & & 49.8 & & \\
\hline $26 \mathrm{R}$ & 177.3 & 126.7 & 54.1 & 31.6 & 27.3 & & 41.7 & & \\
\hline $27 G$ & 177 & 106.5 & 47.6 & & & & & & \\
\hline $28 G$ & 175.7 & 107.8 & 47.6 & & & & & & \\
\hline $29 \mathrm{R}$ & 176.2 & 125 & 58.8 & 32.8 & 27.3 & & 42.7 & & \\
\hline 30R & 176.1 & 117.6 & 58.4 & 32.3 & 27.2 & & 43.5 & & \\
\hline 311 & 176.6 & 125.3 & 58.9 & 40.7 & 27.6 & 17.3 & 14.7 & & \\
\hline $32 W$ & 177.7 & 119.8 & 56.7 & 29.5 & 111.4 & & & & \\
\hline $33 S$ & 176.2 & 121.4 & 57.7 & 67.4 & & & & & \\
\hline $34 \mathrm{G}$ & 172.7 & 110.2 & 43.9 & & & & & & \\
\hline $35 \mathrm{~T}$ & 174.5 & 120.7 & 62.2 & 71.4 & 21.6 & & & & \\
\hline 36R & 178.4 & 116 & 59.4 & 29.9 & 28.5 & & 41.6 & & \\
\hline $37 \mathrm{E}$ & 173.8 & 120 & 55.4 & 33.6 & 37.7 & & 183.8 & & \\
\hline $38 \mathrm{~V}$ & 178.2 & 120 & 66.5 & 31.1 & 23.6 & 21.7 & & & \\
\hline
\end{tabular}




\begin{tabular}{|c|c|c|c|c|c|c|c|c|c|}
\hline 391 & 177.8 & 119.2 & 66.6 & 38.4 & 29.5 & 18.2 & 14.2 & & \\
\hline $40 \mathrm{~A}$ & 178.6 & 118 & 55.5 & 18.3 & & & & & \\
\hline $41 Y$ & 178.5 & 122.6 & 58.7 & 38.6 & 134.8 & & & & \\
\hline $42 G$ & 174.4 & 107 & 47.2 & & & & & & \\
\hline $43 \mathrm{M}$ & 176.9 & 120.8 & 55.3 & 34.2 & 31.3 & & & & 17.3 \\
\hline $44 \mathrm{P}$ & 175.4 & 138.9 & 64.2 & 28.1 & 26.6 & & 50.4 & & \\
\hline $45 \mathrm{~A}$ & 181 & 122.6 & 55.2 & 18.2 & & & & & \\
\hline $46 S$ & 176.5 & 120.6 & 62.2 & 63.2 & & & & & \\
\hline $47 \mathrm{~V}$ & 178.1 & 123 & 66.7 & 31.5 & 23.2 & 21.5 & & & \\
\hline $48 W$ & 178 & 119.6 & 59.5 & 30 & 110.7 & & & & \\
\hline $49 R$ & 178.1 & 120.7 & 58.1 & 27.2 & 28.3 & & 41.1 & & \\
\hline $50 \mathrm{D}$ & 177.3 & 120.2 & 56.4 & 37.6 & 179 & & & & \\
\hline $51 \mathrm{~L}$ & 178 & 116 & 58 & 41.5 & 26.4 & & 23.3 & 22.8 & \\
\hline $52 Y$ & 175.1 & 120 & 61.5 & 37.5 & 131.5 & & & & \\
\hline $53 Y$ & 178.1 & 120.2 & 62.2 & 37.5 & 132.2 & & & & \\
\hline $54 \mathrm{~W}$ & 177 & 121.2 & 61.8 & 29 & 111.3 & & & & \\
\hline $55 \mathrm{~A}$ & 179 & 121 & 55.7 & 18.3 & & & & & \\
\hline $56 \mathrm{~L}$ & 178 & 118.5 & 57.8 & 41.6 & 27 & & 24.2 & 22.8 & \\
\hline $57 \mathrm{~K}$ & 176.6 & 120 & 57.8 & 31.6 & 26.8 & & 29.6 & & \\
\hline $58 \mathrm{~V}$ & 177.4 & 120.2 & 67.4 & 31.5 & 23.4 & 22 & & & \\
\hline $59 S$ & 178.6 & 117.1 & 61.5 & 62.5 & & & & & \\
\hline $60 \mathrm{~W}$ & 176.9 & 123.6 & 59.3 & & 105.8 & & & & \\
\hline $61 \mathrm{P}$ & 175.7 & 138.7 & 64 & 32.2 & 27 & & 50.2 & & \\
\hline $62 \mathrm{~V}$ & 177.3 & 120 & 68.2 & 31.3 & & & & & \\
\hline $63 \mathrm{~F}$ & 176.3 & 120.1 & 62.7 & & & & & & \\
\hline $64 \mathrm{~F}$ & 176.3 & 123.6 & 62.7 & 39.8 & & & & & \\
\hline $65 \mathrm{~A}$ & 179.1 & 118 & 55.7 & 18.3 & & & & & \\
\hline $66 S$ & 176.3 & 115.4 & 63.1 & 62.5 & & & & & \\
\hline $67 \mathrm{~L}$ & 179.4 & 122.4 & 58 & 42 & 27.2 & & 24 & 22.1 & \\
\hline $68 \mathrm{~A}$ & 178.6 & 123.1 & 55.7 & 18.4 & & & & & \\
\hline $69 \mathrm{~A}$ & 177.3 & 123.2 & 55.8 & 18.2 & & & & & \\
\hline $70 \mathrm{~L}$ & 177.9 & 120.8 & 57.8 & 41.7 & 27.2 & & 23.7 & 21.5 & \\
\hline $71 \mathrm{~F}$ & 178.4 & 120 & 62.3 & 37.5 & 139.7 & & 131.4 & & \\
\hline $72 \mathrm{~V}$ & 177.5 & 123.4 & 67.8 & 31.45 & 24 & 22 & & & \\
\hline $73 \mathrm{~V}$ & 177.4 & 120.4 & 67.8 & 31.3 & 23.7 & 21.7 & & & \\
\hline $74 \mathrm{~N}$ & 176.4 & 121 & 58.4 & 37.6 & & & & & \\
\hline $75 \mathrm{~N}$ & 178.7 & 119.5 & 55.7 & 37 & & & & & \\
\hline $76 \mathrm{~T}$ & 175.5 & 117.3 & 66.6 & 68.9 & 21.6 & & & & \\
\hline $77 \mathrm{~L}$ & 178 & 124.1 & 58.3 & 41.6 & 26.6 & & 23.6 & 22.5 & \\
\hline $78 \mathrm{~F}$ & 176.2 & 119.3 & 60.1 & 39.9 & 137.6 & & & & \\
\hline $79 \mathrm{~A}$ & 179.4 & 121.4 & 55.5 & 18.3 & & & & & \\
\hline
\end{tabular}




\begin{tabular}{|c|c|c|c|c|c|c|c|c|c|}
\hline $80 \mathrm{~L}$ & 178.2 & 118.3 & 57.8 & 42.3 & 26.8 & & 23.7 & 21.7 & \\
\hline $81 \mathrm{~L}$ & 178 & 118.7 & 58 & 41.6 & 27 & & 23.7 & 21.7 & \\
\hline $82 Y$ & 177 & 119.9 & 61.3 & 39.1 & 139.3 & & 130.3 & & \\
\hline $83 Q$ & 178.2 & 119.6 & 58.3 & 29.6 & 32.1 & & 180.8 & & \\
\hline $84 \mathrm{~L}$ & 177.6 & 117.7 & 56.3 & 41.8 & & & & & \\
\hline $85 \mathrm{G}$ & 172.7 & 105 & 44.1 & & & & & & \\
\hline $86 \mathrm{D}$ & 175.5 & 121.7 & 54.3 & 42 & & & & & \\
\hline $87 \mathrm{~A}$ & 175.4 & 127.8 & 52.4 & 19 & & & & & \\
\hline $88 \mathrm{P}$ & 176.6 & 132 & 64.9 & 33.9 & 25.9 & & 50.6 & & \\
\hline 891 & 176 & 117.9 & 58.5 & 41.3 & 26.1 & 17.2 & 13.1 & & \\
\hline $90 \mathrm{~A}$ & 176 & 131.7 & 52.3 & 18.5 & & & & & \\
\hline $91 \mathrm{~N}$ & 174.8 & 113 & 53.4 & 37 & 178.7 & & & & \\
\hline $92 \mathrm{Q}$ & 175.8 & 117.7 & 58.2 & 27.1 & 32.35 & & 178.8 & & \\
\hline $93 S$ & 176.1 & 114.1 & 56.4 & 64.5 & & & & & \\
\hline $94 \mathrm{P}$ & & 137 & 63.7 & 32 & 27.2 & & 50.1 & & \\
\hline $95 \mathrm{P}$ & 177.5 & 129.3 & 61.45 & 31.4 & 26.6 & & 50.8 & & \\
\hline $96 \mathrm{G}$ & 176.1 & 108.3 & 46.8 & & & & & & \\
\hline $97 \mathrm{~F}$ & 178.4 & 125 & 58.6 & 39.4 & & & & & \\
\hline $98 \mathrm{~V}$ & 177.8 & 118.6 & 67.2 & 31.2 & 24 & 21.4 & & & \\
\hline $99 G$ & 175.9 & 111.3 & 48 & & & & & & \\
\hline $100 \mathrm{~A}$ & 179 & 122.6 & 55.2 & 17.7 & & & & & \\
\hline $101 \mathrm{~F}$ & 176.9 & 120.6 & 62 & 37.6 & & & 131.9 & & \\
\hline $102 \mathrm{~F}$ & 178.4 & 119 & 61.7 & 37.6 & & & 130.9 & & \\
\hline $103 \mathrm{~F}$ & 176.8 & 122.6 & 61.8 & 38.1 & 137.9 & & 130.6 & & \\
\hline $104 S$ & 176.2 & 115 & 62.3 & 63.1 & & & & & \\
\hline $105 \mathrm{~V}$ & 177.4 & 123.6 & 67.6 & 31.4 & 21.5 & 23.6 & & & \\
\hline $106 \mathrm{E}$ & 178.2 & 118 & 58.2 & 27.3 & 36.1 & & 182.8 & & \\
\hline $107 \mathrm{~T}$ & 175.8 & 117.6 & 61.6 & 70.8 & 21.8 & & & & \\
\hline $108 \mathrm{~L}$ & 178.3 & 118.4 & 58.1 & 40.8 & 27 & & & & \\
\hline $109 \mathrm{~A}$ & 179 & 112.8 & 51.5 & 20.5 & & & & & \\
\hline $110 \mathrm{~T}$ & 172.2 & 110.7 & 62.6 & 70.1 & 20.9 & & & & \\
\hline $111 \mathrm{~V}$ & 179.1 & 120.8 & 65.6 & 33.5 & 22.45 & 20.4 & & & \\
\hline $112 \mathrm{G}$ & 175.1 & 103.8 & 48.5 & & & & & & \\
\hline $113 Y$ & 177.3 & 116.2 & 61 & 39.8 & 130 & & & & \\
\hline $114 \mathrm{G}$ & 174.5 & 106.6 & 46.6 & & & & & & \\
\hline $115 \mathrm{D}$ & 176.1 & 121 & 54.5 & 41.7 & 178.9 & & & & \\
\hline $116 \mathrm{M}$ & 175.4 & 116.3 & 55.1 & 32.9 & 36.1 & & & & 18.1 \\
\hline $117 \mathrm{H}$ & 169.5 & 114.8 & 52.9 & 26 & 128.4 & & & & \\
\hline $118 \mathrm{P}$ & 176.6 & 137.4 & 62.6 & 30.9 & 27.9 & & 50.3 & & \\
\hline $119 Q$ & 174.4 & 115.8 & 53.8 & 29.2 & 30.9 & & & & \\
\hline $120 \mathrm{~T}$ & 174.3 & 111.3 & 58.5 & 72 & 23.3 & & & & \\
\hline
\end{tabular}




\begin{tabular}{|c|c|c|c|c|c|c|c|c|c|}
\hline $121 \mathrm{~V}$ & 177.4 & 124.2 & 68.3 & 31.4 & 24.2 & 22.1 & & & \\
\hline $122 Y$ & 176.8 & 120.5 & 62.2 & 37.5 & 130.3 & & & & \\
\hline $123 \mathrm{~A}$ & 177.2 & 119.5 & 54.8 & 17.5 & & & & & \\
\hline $124 \mathrm{H}$ & 177.4 & 118.2 & 58.1 & 27.8 & & & & & \\
\hline $125 \mathrm{~A}$ & 177.7 & 122 & 55.7 & 18.2 & & & & & \\
\hline 1261 & 177.1 & 119 & 64.1 & 37.8 & 26.9 & 17.3 & 13.8 & & \\
\hline $127 \mathrm{~A}$ & 178.2 & 120.7 & 56.5 & 18.4 & & & & & \\
\hline $128 \mathrm{~T}$ & 175.6 & 119 & 68.6 & 68 & 21.8 & & & & \\
\hline $129 \mathrm{~L}$ & 178.3 & 120.9 & 58.5 & 41.4 & 26.7 & & 23.8 & 21.7 & \\
\hline $130 \mathrm{E}$ & 176.4 & 119.1 & 59.9 & 28 & 36.8 & & 180.1 & & \\
\hline $131 \mathrm{C}$ & 177.1 & 119.6 & 65.1 & 29.6 & & & & & \\
\hline $132 \mathrm{~F}$ & 178.7 & 120.2 & 62.1 & 39 & & & & & \\
\hline $133 \mathrm{~V}$ & 177 & 122.8 & 67.1 & 31.5 & 23.8 & 23.2 & & & \\
\hline $134 \mathrm{G}$ & 175.8 & 106.8 & 48 & & & & & & \\
\hline $135 \mathrm{M}$ & 175.3 & 122.4 & 58.3 & 32.8 & 35.2 & & & & 17.1 \\
\hline $136 S$ & 175.7 & 114.7 & 63.2 & 64.3 & & & & & \\
\hline $137 \mathrm{G}$ & 177.4 & 110.5 & 47.5 & & & & & & \\
\hline 1381 & 179.1 & 126.5 & 66.3 & 38.5 & 27 & 17 & 13.6 & & \\
\hline $139 \mathrm{~A}$ & 179.4 & 125.8 & 56.3 & 18.4 & & & & & \\
\hline $140 \mathrm{~L}$ & 178.5 & 118.7 & 58.1 & 41.3 & 26.8 & & 23.3 & 22.5 & \\
\hline $141 \mathrm{~s}$ & 177.1 & 114.7 & 63.3 & 62.6 & & & & & \\
\hline $142 \mathrm{~T}$ & 176.2 & 120 & 67.9 & 67.4 & 21.7 & & & & \\
\hline $143 G$ & 175.8 & 110.2 & 48.1 & & & & & & \\
\hline $144 \mathrm{~L}$ & 178.2 & 122.6 & 58 & 41.4 & 27.3 & & 23.7 & 21.6 & \\
\hline $145 \mathrm{~V}$ & 178.9 & 120.2 & 67.1 & 31.6 & 24.3 & 22.1 & & & \\
\hline $146 \mathrm{~F}$ & 176.3 & 124 & 62.5 & 39.8 & 137.7 & & & & \\
\hline $147 \mathrm{~A}$ & 179.2 & 120.8 & 55.6 & 18.3 & & & & & \\
\hline $148 \mathrm{R}$ & 177.5 & 118.2 & 58.3 & 29.7 & 26.6 & & 44.8 & & \\
\hline $149 \mathrm{~F}$ & 174.4 & 120.1 & 60.6 & 37.3 & 136.5 & & & & \\
\hline $150 \mathrm{~A}$ & 174.7 & 125.4 & 54.3 & 18 & & & & & \\
\hline $151 \mathrm{R}$ & 171.9 & 125.5 & 54.6 & 33.3 & 26.3 & & 42.9 & & \\
\hline $152 \mathrm{P}$ & 175.2 & 135.5 & 61.5 & 29.8 & 27.5 & & 50.5 & & \\
\hline $153 R$ & 175.1 & 121.8 & 55.5 & 32.8 & 26.8 & & 42.1 & & \\
\hline $154 \mathrm{~A}$ & 177.3 & 120.2 & 55.4 & 22.2 & & & & & \\
\hline $155 \mathrm{~K}$ & 179.7 & 120.7 & 57.9 & 32.2 & 25.1 & & 28.7 & & 40.7 \\
\hline $156 I$ & 177.8 & 121.8 & 64.6 & 37.9 & 29.7 & 17.8 & 14.1 & & \\
\hline $157 M$ & 174.8 & 117.6 & 58.3 & 32.3 & 35.7 & & & & 16.9 \\
\hline $158 \mathrm{~F}$ & 176.8 & 124.3 & 55.4 & 41.3 & 139.6 & & & & \\
\hline $159 \mathrm{~A}$ & 175.3 & 118.3 & 54.7 & 19.2 & & & & & \\
\hline $160 \mathrm{R}$ & 174.7 & 122.7 & 54.3 & 34.6 & 27.6 & & 44 & & \\
\hline $161 \mathrm{H}$ & 176.1 & 120.6 & 53.8 & 32.8 & 128.3 & & & & \\
\hline
\end{tabular}




\begin{tabular}{|c|c|c|c|c|c|c|c|c|c|}
\hline $162 A$ & 175.2 & 123.3 & 53.4 & 21.7 & & & & & \\
\hline $163 \mid$ & 177.5 & 117.7 & 57.8 & 42.6 & 28.3 & 18.1 & 13.2 & & \\
\hline $164 \mathrm{~V}$ & 175 & 118.6 & 59.9 & 32.5 & 21.3 & 22 & & & \\
\hline $165 R$ & 175.7 & 122.6 & 56 & 31.2 & 26.9 & & 42.2 & & \\
\hline 166P & 176.2 & 132 & 62.8 & 32.1 & 27 & & 51.5 & & \\
\hline $167 \mathrm{~F}$ & 177.8 & 120.7 & 55.1 & 41.5 & 140 & & & & \\
\hline $168 \mathrm{~N}$ & 177 & 121 & 55.2 & 35.3 & 176 & & & & \\
\hline $169 \mathrm{G}$ & 174.2 & 107.7 & 45.1 & & & & & & \\
\hline 170R & 175.3 & 120.5 & 53.6 & 33 & 26.6 & & 47 & & \\
\hline $171 \mathrm{M}$ & 174.5 & 115.8 & 53.7 & 30.7 & 29.2 & & & & 17.5 \\
\hline $172 \mathrm{~T}$ & 174.5 & 111.7 & 58.9 & 71.9 & 21.9 & & & & \\
\hline 173L & 176.3 & 116.8 & 54.8 & 44.5 & 25.8 & & 22.6 & 22.1 & \\
\hline $174 M$ & 178 & 121.1 & 55.5 & 36.6 & 31.6 & & & & 18.1 \\
\hline $175 \mathrm{~V}$ & 176.5 & 121.8 & 61.3 & 34.1 & 22.7 & 21.3 & & & \\
\hline 176R & 175.9 & 121 & 55.1 & 32.7 & 27.5 & & 41.8 & & \\
\hline $177 \mathrm{~A}$ & 176.4 & 124.4 & 52.6 & 19.6 & & & & & \\
\hline $178 \mathrm{~A}$ & 178 & 120.4 & 52.2 & 19.9 & & & & & \\
\hline $179 \mathrm{~N}$ & 176.4 & 113.2 & 53.2 & 37.1 & 178.5 & & & & \\
\hline $180 \mathrm{~A}$ & 174.6 & 121.2 & 53.8 & 18.2 & & & & & \\
\hline 181R & 174.5 & 118.3 & 56.4 & 29.5 & 27.42 & & 43.1 & & \\
\hline $182 \mathrm{Q}$ & 176.2 & 121.8 & 54.4 & 29.8 & 31.5 & & 180.6 & & \\
\hline $183 \mathrm{~N}$ & 177.4 & 120.4 & 55.6 & 37.8 & 180 & & & & \\
\hline $184 \mathrm{~V}$ & 178 & 117 & 66.6 & 31.6 & 23.4 & 21.9 & & & \\
\hline $185 I$ & 177.9 & 120 & 59.8 & 42.3 & 28.5 & 17.8 & 15.1 & & \\
\hline $186 \mathrm{~A}$ & 175.1 & 118.8 & 53.2 & 19.4 & & & & & \\
\hline $187 \mathrm{E}$ & 174.1 & 125.8 & 53.8 & 31.6 & 35.5 & & 182.3 & & \\
\hline $188 \mathrm{~A}$ & 175.3 & 126.8 & 51.1 & 20.7 & & & & & \\
\hline $189 R$ & 175.2 & 121.5 & 54.3 & 32.6 & 26.6 & & 43.9 & & \\
\hline $190 \mathrm{~A}$ & 176 & 127.8 & 52.6 & 19.1 & & & & & \\
\hline $191 K$ & 174.7 & 116.8 & 54.4 & 32.4 & 25.2 & & 29 & & 42.8 \\
\hline $192 M$ & 174.5 & 124 & 54 & 34.3 & 33 & & & & 17.9 \\
\hline $193 R$ & 174.6 & 123.3 & 53.1 & 33.7 & 26.6 & & 45.8 & & \\
\hline $194 \mathrm{~L}$ & 174.4 & 124.1 & 54.6 & 41 & 27.8 & & 23.3 & 23.6 & \\
\hline $195 \mathrm{M}$ & 175.6 & 115.4 & 55 & 36.2 & 32.8 & & & & 18.8 \\
\hline 196R & 176 & 113.4 & 56.6 & 31.3 & 26.3 & & 41.6 & & \\
\hline 197R & 175.1 & 119.4 & 56.3 & 31.7 & 26.9 & & 43 & & \\
\hline $198 \mathrm{E}$ & 177 & 118.5 & 58.8 & 30.6 & 35.9 & & 182.4 & & \\
\hline $199 \mathrm{H}$ & 177.5 & 120.1 & 56.6 & 31.5 & 131.7 & & & & \\
\hline $200 \mathrm{~S}$ & 177.9 & 115.3 & 58.1 & 63.9 & & & & & \\
\hline $201 \mathrm{~S}$ & 177 & 116.5 & 55.4 & 64.2 & & & & & \\
\hline $202 \mathrm{E}$ & 175.4 & 120 & 57.4 & 29.7 & 37.4 & & 182.8 & & \\
\hline
\end{tabular}




\begin{tabular}{|c|c|c|c|c|c|c|c|c|c|}
\hline $203 G$ & 175.7 & 106.2 & 47.6 & & & & & & \\
\hline $204 Y$ & 176.5 & 120.2 & 59.4 & 37 & 131.3 & & & & \\
\hline $205 S$ & 176.2 & 119.9 & 55.8 & 63.7 & & & & & \\
\hline $206 \mathrm{~L}$ & 176.3 & 121.9 & 54.6 & 42.3 & 28.3 & & 25.6 & 26.8 & \\
\hline $207 \mathrm{M}$ & 175.7 & 121.2 & 54.4 & 33.7 & 31.9 & & & & 18 \\
\hline $208 \mathrm{~K}$ & 176.5 & 117.1 & 54.9 & 32.6 & 24.8 & & 29.5 & & 40.8 \\
\hline 2091 & 177.5 & 118.7 & 58.9 & 42 & 27.2 & 18.1 & 13.7 & & \\
\hline $210 \mathrm{H}$ & 178.1 & 124 & 55.3 & 32.5 & 130.7 & & & & \\
\hline 211D & 176.1 & 122.8 & 54 & 39.9 & 178.9 & & & & \\
\hline $212 \mathrm{~L}$ & 177.8 & 117.8 & 55.6 & 41.6 & 25.9 & & 21.8 & 23.3 & \\
\hline $213 K$ & 177.6 & 118 & 58.1 & 31.7 & 26.5 & & 27.8 & & 41.6 \\
\hline $214 \mathrm{~L}$ & 179.5 & 116 & 58 & 40.8 & 27.6 & & 22.8 & 22.1 & \\
\hline $215 \mathrm{~V}$ & 176.7 & 120 & 65.3 & 31.8 & 22.9 & 21.8 & & & \\
\hline $216 R$ & 179.7 & 117.9 & 59.6 & 29.8 & 28.4 & & 42 & & \\
\hline $217 \mathrm{~N}$ & 178.6 & 118.6 & 53.4 & 42.4 & 175.1 & & & & \\
\hline $218 \mathrm{E}$ & 177.1 & 117.3 & 58.8 & 29.4 & 36 & & 181 & & \\
\hline $219 \mathrm{H}$ & 177.2 & 120.6 & 55.7 & 31 & 130.6 & & & & \\
\hline $220 \mathrm{P}$ & 179.2 & 142.4 & 64.1 & 32.3 & 26.8 & & 50.6 & & \\
\hline 2211 & 178 & 118.9 & 66 & 38.4 & 29.4 & 17.3 & 14.1 & & \\
\hline $222 \mathrm{~F}$ & 176.5 & 117 & 57.3 & 41.3 & 137.7 & & 132.1 & & \\
\hline $223 \mathrm{~L}$ & 176.4 & 121.6 & 56.4 & 41.8 & 26 & & 24.2 & 23.7 & \\
\hline $224 \mathrm{~L}$ & 177.5 & 118 & 56.4 & 41.9 & 26.2 & & 23.7 & 23.3 & \\
\hline $225 \mathrm{G}$ & 174 & 105.2 & 45.1 & & & & & & \\
\hline $226 \mathrm{~W}$ & 176.6 & 118.3 & 55.4 & 29.4 & & & & & \\
\hline $227 \mathrm{~N}$ & 176.2 & 125.9 & 52.8 & 40.3 & 174.7 & & & & \\
\hline $228 \mathrm{M}$ & 176.2 & 116.2 & 55.6 & 32.3 & 31.3 & & & & 17.8 \\
\hline $229 \mathrm{M}$ & 176.4 & 119.3 & 55.8 & 34 & 31.6 & & & & 18.3 \\
\hline $230 \mathrm{H}$ & 177.1 & 118.3 & 55.6 & 30.4 & 133.9 & & & & \\
\hline $231 \mathrm{~V}$ & 178.5 & 119.5 & 59.9 & 33.9 & 22.1 & 21.2 & & & \\
\hline 2321 & 177.4 & 119.4 & 65.2 & 37.8 & 26.9 & 16.9 & 14.2 & & \\
\hline $233 \mathrm{D}$ & 177.8 & 121.4 & 54.4 & 40.9 & 178.9 & & & & \\
\hline $234 \mathrm{E}$ & 176.7 & 115.7 & 57.6 & 30.2 & 34.4 & & 182.8 & & \\
\hline $235 \mathrm{~S}$ & 177.2 & 121.6 & 55.7 & 68.3 & & & & & \\
\hline $236 \mathrm{~S}$ & & 123.8 & 58.4 & 64 & & & & & \\
\hline $237 \mathrm{P}$ & 176.8 & 134.6 & 65.4 & 29.6 & 26.6 & & 50.4 & & \\
\hline $238 \mathrm{~L}$ & 178 & 115.7 & 56 & 42.1 & 26.2 & & 22.5 & 21.9 & \\
\hline $239 \mathrm{~F}$ & 177.4 & 114.8 & 63.1 & 37.8 & & & 132.3 & & \\
\hline $240 \mathrm{G}$ & 175.7 & 110 & 47.9 & & & & & & \\
\hline $241 \mathrm{E}$ & 176.8 & 121.2 & 58.2 & 32.4 & 36.1 & & 180.1 & & \\
\hline $242 \mathrm{~T}$ & 173.7 & 112 & 59.7 & 72.9 & & 21.7 & & & \\
\hline $243 \mathrm{P}$ & 176.1 & 139.5 & 63.1 & 31.2 & 29.2 & & 50.7 & & \\
\hline
\end{tabular}




\begin{tabular}{|c|c|c|c|c|c|c|c|c|c|}
\hline $244 \mathrm{E}$ & 176.5 & 122.7 & 59.1 & 28.8 & 36 & & 180.7 & & \\
\hline $245 S$ & 176.1 & 118.1 & 62.7 & 63 & & & & & \\
\hline $246 \mathrm{~L}$ & 179.3 & 121.6 & 58.2 & 41.9 & 26.7 & & 23.5 & 23.1 & \\
\hline $247 \mathrm{~A}$ & 179.5 & 122.1 & 55.4 & 18.1 & & & & & \\
\hline $248 \mathrm{E}$ & 176.7 & 120 & 58.4 & 27.6 & 38.4 & & 181.9 & & \\
\hline $249 G$ & 174.8 & 107.4 & 45.5 & & & & & & \\
\hline $250 R$ & 176.7 & 123.5 & 54.4 & 27.6 & 25.6 & & 41.9 & & \\
\hline $251 \mathrm{~A}$ & 175 & 121.3 & 54.6 & 18.2 & & & & & \\
\hline $252 M$ & 175.6 & 120.4 & 54 & 34.4 & 32.6 & & & & 17.5 \\
\hline $253 \mathrm{~L}$ & 178.5 & 120.5 & 54.5 & 43.3 & 27.3 & & 22.8 & 21.6 & \\
\hline $254 \mathrm{~L}$ & 174.9 & 120.3 & 54.5 & 45.5 & 27.2 & & 22.6 & 21.8 & \\
\hline $255 \mathrm{~V}$ & 178.2 & 119.1 & 60.3 & 34 & 22.2 & 21.3 & & & \\
\hline $256 \mathrm{M}$ & 174.6 & 117.6 & 55 & 36.1 & 34.5 & & & & 18 \\
\hline 2571 & 176 & 117.6 & 59 & 41.3 & 27.6 & 17.1 & 13 & & \\
\hline $258 \mathrm{E}$ & 175.5 & 118 & 56.3 & 30.5 & 37.6 & & 182.6 & & \\
\hline $259 G$ & 172.7 & 104.8 & 44.1 & & & & & & \\
\hline $260 \mathrm{~S}$ & 176 & 122 & 55.1 & 63.1 & & & & & \\
\hline 261D & 177.7 & 120.1 & 55.7 & 42.7 & 179.3 & & & & \\
\hline $262 \mathrm{E}$ & 175.5 & 117.9 & 58.1 & 31.7 & 35.4 & & 183 & & \\
\hline $263 \mathrm{~T}$ & 177.2 & 117.2 & 60.1 & 67 & & 21.5 & & & \\
\hline $264 \mathrm{~T}$ & 174.9 & 121 & 60.4 & 70.1 & & 21.2 & & & \\
\hline $265 \mathrm{~A}$ & 175.4 & 129.4 & 50.4 & 20.3 & & & & & \\
\hline $266 \mathrm{Q}$ & 174.5 & 122.1 & 54.9 & 31.3 & 32.9 & & 180.4 & & \\
\hline $267 \mathrm{~V}$ & 175.2 & 123.4 & 61.1 & 34.4 & 21.1 & 20.4 & & & \\
\hline $268 \mathrm{M}$ & 176.2 & 126 & 54.2 & 35.4 & 33.4 & & & & 17.6 \\
\hline $269 \mathrm{Q}$ & 175.3 & 118.3 & 55.3 & 33.4 & 34.6 & & 179.4 & & \\
\hline $270 \mathrm{~A}$ & 175.9 & 126 & 52.4 & 21.9 & & & & & \\
\hline $271 R$ & 175 & 125.9 & 54.3 & 31.6 & 26.8 & & 44.5 & & \\
\hline $272 \mathrm{H}$ & 174.5 & 124 & 55.7 & 32.5 & 130.1 & & & & \\
\hline $273 A$ & 176.9 & 127.4 & 52.8 & 20.4 & & & & & \\
\hline $274 W$ & 178.8 & 122.7 & 58.7 & 34.5 & 111.1 & & & & \\
\hline $275 \mathrm{E}$ & 174.5 & 115.8 & 55.4 & 31.3 & 34.1 & & 182.2 & & \\
\hline $276 \mathrm{H}$ & 175.8 & 123.1 & 59.9 & 27.3 & 133.4 & & & & \\
\hline $277 \mathrm{D}$ & 178.6 & 122.5 & 55.9 & 39.3 & 176 & & & & \\
\hline $278 \mathrm{D}$ & 177 & 117.8 & 55.6 & 37.5 & 178.6 & & & & \\
\hline 2791 & 177.5 & 120.4 & 57.9 & 41.2 & 27 & 18.2 & 14.1 & & \\
\hline $280 \mathrm{R}$ & 174.6 & 124.2 & 55.1 & 34.8 & 27 & & 42.1 & & \\
\hline $281 \mathrm{~W}$ & 178.2 & 124.6 & 55.7 & 33 & & & & & \\
\hline $282 \mathrm{H}$ & 178.9 & 115.7 & 59.5 & 26 & & & & & \\
\hline $283 \mathrm{H}$ & 178.7 & 119.8 & 58.2 & 27 & & & & & \\
\hline $284 \mathrm{R}$ & 179.1 & 123.9 & 55.2 & 32.3 & 27.5 & & 41.2 & & \\
\hline
\end{tabular}




\begin{tabular}{|c|c|c|c|c|c|c|c|c|c|}
\hline $285 Y$ & 176 & 121.3 & 61.7 & 39.6 & 132.2 & & & & \\
\hline $286 \mathrm{~V}$ & 178.6 & 123.1 & 61.6 & 32.9 & 22.5 & 21.3 & & & \\
\hline 287D & 174.6 & 121.1 & 55.6 & 44.6 & 176.7 & & & & \\
\hline $288 \mathrm{~L}$ & 176.9 & 116.2 & 57.8 & 41 & 26.5 & & 23.5 & 22.7 & \\
\hline $289 \mathrm{M}$ & 178.6 & 119.2 & 55.6 & 34.2 & 31.6 & & & & 17.7 \\
\hline $290 \mathrm{~S}$ & 176.9 & 121.5 & 56.8 & 63.7 & & & & & \\
\hline 291D & 174.7 & 124.2 & 54.8 & 41.1 & 176.1 & & & & \\
\hline $292 \mathrm{~V}$ & 174.6 & 122.7 & 60.8 & 33.3 & 21.3 & 21.6 & & & \\
\hline 293D & 176.4 & 125.8 & 54.7 & 42.8 & 174.5 & & & & \\
\hline $294 \mathrm{G}$ & 173.9 & 107 & 45.7 & & & & & & \\
\hline $295 \mathrm{M}$ & 177 & 121.5 & 54.5 & 33.7 & 31.7 & & & & 18 \\
\hline $296 \mathrm{~T}$ & 172.6 & 117.9 & 61.3 & 70.8 & & 21.2 & & & \\
\hline $297 \mathrm{H}$ & 174.3 & 125.8 & 55.1 & 33.6 & 130.3 & & & & \\
\hline 2981 & 174.8 & 126.7 & 60.5 & 42.5 & 27.4 & 17.4 & 14.4 & & \\
\hline $299 D$ & 176.3 & 127.4 & 54.3 & 43 & 174.6 & & & & \\
\hline $300 Y$ & 176 & 119.6 & 55 & 39.5 & 131.1 & & 136.7 & & \\
\hline $301 \mathrm{~T}$ & & 117.7 & 61.7 & 70.8 & & 23.9 & & & \\
\hline
\end{tabular}

